\title{
Oxycodone self-administration activates the mitogen-activated protein kinase/ mitogen- and stress-activated protein kinase (MAPK-MSK) signaling pathway in the rat dorsal striatum
}

Christopher A. Blackwood, Michael T. McCoy, Bruce Ladenheim, and Jean Lud Cadet*

Molecular Neuropsychiatry Research Branch, NIH/NIDA Intramural Research Program

251 Bayview Boulevard, Baltimore, MD 21224

\section{Address correspondence to:}

*Jean Lud Cadet, M.D.

Molecular Neuropsychiatry Research Branch

NIH/NIDA Intramural Research Program

251 Bayview Boulevard

Baltimore, MD 21224

(443) 740-2656 Phone

(443) 740-2856 FAX

jcadet@intra.nida.nih.gov

Title: 20 words; Abstract: 149 words; Main Text: 4,118 words;

No. of Figs.: 9; Supplemental Figs.: 4; No. of tables: 0; Supplemental tables: 2 


\section{ABSTRACT}

To identify signaling pathways activated by oxycodone self-administration (SA), Sprague-Dawley rats self-administered oxycodone for 20 days using short-access (ShA, $3 \mathrm{~h}$ ) and long-access ( $\mathrm{LgA}, 9 \mathrm{~h}$ ) paradigms. Animals were euthanized two hours after SA cessation and dorsal striata were used in post-mortem molecular analyses. LgA rats escalated their oxycodone intake and separated into lower ( $\mathrm{LgA}-\mathrm{L})$ or higher $(\mathrm{LgA}-\mathrm{H})$ oxycodone takers. LgA-H rats showed increased striatal protein phosphorylation of ERK1/2 and MSK1/2. Histone H3, phosphorylated at serine 10 and acetylated at lysine 14 (H3S10pK14Ac), a MSK1/2 target, showed increased abundance only in LgA-H rats. RT-qPCR analyses revealed increased AMPA receptor subunits, GluA2 and G/uA3 mRNAs in the LgA-H rats. GluA3, but not GluA2, expression correlated positively with changes in pMSK1/2 and H3S10pK14Ac. Our findings indicate that escalated oxycodone SA results in MSK1/2-dependent histone phosphorylation, which promoted increases in striatal gene expression. Our observations offer novel avenues for pharmacological interventions against oxycodone addiction.

Keywords: Oxycodone, Kinases, Protein Phosphorylation, MSK, Dorsal Striatum, Histone phosphoacetylation 


\section{Introduction}

The opioid epidemic remains a public health crisis ${ }^{1,2}$. This is related, in part, to the overprescription of the opioid agonist, oxycodone, for pain management ${ }^{3-6}$. Its illicit abuse has also contributed to the high number of overdose-related deaths ${ }^{7,8}$. Other complications of oxycodone use disorder include moderate to severe withdrawal symptoms ${ }^{1}$ and repeated episodes of relapses during attempts to quit through psychological or pharmacological interventions ${ }^{9}$. Chronic use of opioid drugs is also accompanied by cognitive deficits ${ }^{10}$ and post-mortem evidence of neuropathological abnormalities in the brain ${ }^{11}$. These biopsychosocial complications make the development of effective treatment of paramount importance.

Pharmacological approaches to treat opioid use disorders (OUDs) have mainly included the use of agents that interact with opioids receptors ${ }^{3,12,13}$. Upon activation, opioid receptors transmit signals to the nucleus via intracellular events that involve modulation of some kinase cascades ${ }^{14-16}$, with consequent changes in gene expression 17,18. Because of several of these experiments had done using in vitro systems, it was important to address the potential neurobiological impact of repeated oxycodone selfadministration in humans by using model systems that better mimic human conditions. Therefore, we decided to use the model of escalated oxycodone self-administration (SA) in rats ${ }^{19,20}$ to identify potential biochemical and molecular pathways that might be perturbed by this drug.

Herein, we used that model to measure alterations in various proteins that may impact the flow of intracellular signals from the mu opioid receptor consequent to its repeated interactions with oxycodone during a drug SA experiment. The rat dorsal striatum was dissected and processed for biochemical and molecular analyses because this structure is thought to play essential roles in the manifestation of habitual drug 
taking behaviors ${ }^{21-23}$. Thus, we report that the mitogen-activated protein kinase $(\mathrm{MAPK}) /$ mitogen- and stress-activated protein kinase (MSK) signaling cascade is activated preferentially in rats that consume large quantities of oxycodone over a period of 20 days. This was manifested by increased phosphorylation of extracellular signalregulated kinases $1 / 2(E R K 1 / 2), M S K 1 / 2$, and increased abundance of histone $\mathrm{H} 3$ phosphorylated at serine 10 and acetylated at lysine 14 (H3S10pK14Ac). Altogether, these findings implicate the role of MAPK/MSK pathway and histone $\mathrm{H} 3$ phosphoacetylation in opioid use disorder.

\section{Materials and Methods}

\section{Intravenous surgery}

We used male Sprague Dawley rats (Charles River, Raleigh, NC, USA), weighing 350$400 \mathrm{~g}$ before surgery and housed on a $12 \mathrm{~h}$ reversed light/dark cycle with food and water freely available. All procedures followed the guidelines outlined in the National Institutes of Health $(\mathrm{NIH})$ Guide for the Care and Use of Laboratory Animals (eighth edition, https://guide-for-the-care-and-use-of-laboratory-animals.pdf) as approved by the NIDA (National Institute of Drug Abuse) Animal Care and Use Committee at the Intramural Research Program (IRP). Catheter implantations were performed as previously described ${ }^{24}$. Briefly, we anesthetized the rats with ketamine $(50 \mathrm{mg} / \mathrm{kg})$ and xylazine $(5$ $\mathrm{mg} / \mathrm{kg}$ ). Polyurethane catheters (SAI Infusion Technologies, Lake Villa, IL) were inserted into the jugular vein. The other end of the catheter was attached to a modified 22-gauge cannula (Plastics One, Roanoke, VA) that was mounted to the back of each rat. The modified cannulas, which served as infusion ports for the catheters, were connected to a fluid swivel (Instech, Plymouth, PA) via polyethylene-50 tubing that was protected by a metal spring. When the infusion ports were not used they were sealed using dust caps 
(PlasticOne, Roanoke, VA). Thereafter, the catheters were flushed every $48 \mathrm{~h}$ with gentamicin $(0.05 \mathrm{mg} / \mathrm{kg}$, Henry Schein, Melville, NY) in sterile saline to maintain patency. Intraperitoneal injection of buprenorphine $(0.1 \mathrm{mg} / \mathrm{kg})$ was used post-surgery to relieve pain.

\section{Apparatus}

Rats were trained in Med Associates SA chambers located inside sound-attenuated cabinets and controlled by a Med Associates System (Med Associates, St Albans, VT) as previously described ${ }^{19}$. In brief, each chamber was equipped with two levers located $8.5 \mathrm{~cm}$ above the grid floor. Presses on the retractable active lever activated the infusion pump and tone-light cue. Presses on the inactive lever had no reinforced consequences.

\section{Training phase}

Rats $(n=42)$ were randomly assigned to either saline (Sal) $(n=8)$ or oxycodone $(n=33)$ conditions. Rats were trained to self-administer oxycodone-HCL (NIDA Pharmacy, Baltimore, MD) for one $3 \mathrm{~h}$ daily session for the short-access (ShA) condition $(n=10)$ or one to three $3 \mathrm{~h}$ sessions for long-access ( $\operatorname{LgA})$ condition $(n=23)$ (Fig. 1A). For the $\operatorname{LgA}$ group, the $3 \mathrm{~h}$ sessions were separated by 30 mins intervals from day 6 to day 20 (Fig. 1A). Lever presses were reinforced using a fixed ratio-1 with a 20-s timeout accompanied by a 5-s compound tone-light cue. We used a scheduling pattern of 5 days of drug SA and 2 days off to control for weight loss, a common side effect of oxycodone intake in laboratory animals ${ }^{25}$. Rats self-administered oxycodone at a dose of $0.1 \mathrm{mg} / \mathrm{kg}$ per infusion over 3.5-s $(0.1 \mathrm{ml}$ per infusion). The house light was turned off, and the active lever retracted at the end of the $3 \mathrm{~h}$ session.

\section{Tissue Collection}


Rats were euthanized $2 \mathrm{~h}$ after training day 20. Dorsal striata tissue was dissected as previously described ${ }^{26}$. In brief, we used stereotaxic coordinates $(A / P+2$ to $-2 \mathrm{~mm}$ bregma, $\mathrm{M} / \mathrm{L} \pm 2$ to $5 \mathrm{~mm}, \mathrm{D} / \mathrm{V}-3$ to $-6 \mathrm{~mm}$ ) according to the rat atlas ${ }^{27}$ and we used the position of anatomical structures (corpus callosum and lateral ventricles) for further accuracy. In brief, the dorsal striata was removed from the skulls and snap frozen on dry ice. Tissue was later used for western blotting and quantitative RT-PCR experiments.

\section{Western blotting}

Western blotting was conducted as previously described ${ }^{19}$. Ten - twenty $\mu$ g of lysate was prepared in solutions that contained 1x NuPage LDS Sample Buffer (ThermoFisher Scientific, Waltham, MA), and $1 \% \beta$-Mercaptoethanol. Protein samples were heated to $70^{\circ} \mathrm{C}$ and loaded on 3-8\% Tris-Acetate Protein Gels (ThermoFisher Scientific, Waltham, MA) or NuPAGE $4-12 \%$ Bis-Tris Protein Gels (ThermoFisher Scientific, Waltham, MA). Proteins were electrophoretically transferred on the Trans-Blot ${ }^{\circledR}$ Turbo ${ }^{\mathrm{TM}}$ system (BioRad, Hercules, CA). Membrane blocking, antibody incubations, and chemiluminescence reactions were performed according to the manufacturer's instructions. Primary and secondary antibodies are listed in Supplemental Table S1. Supplemental Table S1 also includes Research Resource Identifiers (RRIDs) where antibodies were previously validated. All antibodies ran at approximate predicted sizes according to manufacturer's instructions. Cyclophilin B or alpha-tubulin was used as loading controls. Following secondary antibody incubation, ECL clarity (Bio-Rad, Hercules, CA) was used to visualize gel bands on ChemiDoc Touch Imaging System (Bio-Rad, Hercules, CA), and intensities were quantified with Image Lab version 6.0 (Bio-Rad, Hercules, CA) software.

\section{Quantitative PCR}


Total RNA was collected as previously described ${ }^{19}$. PCR experiments were performed using the LightCycler 480 II (Roche Diagnostics, Indianapolis, IN) with iQ SYBR Green Supermix (Bio-Rad, Hercules, CA). Primers were purchased from Johns Hopkins University (Baltimore, MD) Synthesis and Sequence Facility. Primer sequences are listed in Supplementary Table S2. The data was normalized to Qaz1 or B2m reference genes. The standard curve method was used to analyze data and the results are reported as fold change relative to Sal.

\section{Statistical Analyses}

Behavioral data were analyzed using either one-way or two-way analysis of variance (ANOVA) as previously described ${ }^{19}$. In brief, dependent variables were the number of oxycodone infusions on training days. Independent variables were between-subject factor reward types (Sal, ShA, LgA-L, LgA-H), within-subject factor SA day (training days 1-20), and their interactions. If the main effects were significant $(p<0.05)$, Bonferroni post hoc tests were used to compare reward types on each training day. Biochemical data were analyzed using one-way ANOVA followed by the Fisher's PLSD post hoc test. Regression analyses were performed using the correlation function in Prism version 8.3.0 (GraphPad Software, San Diego, CA). Statistical significance for all hypothesis tests was set at $p<0.05$. Behavioral and biochemical data were analyzed with Prism version 8.3.0 (GraphPad Software, San Diego, CA).

\section{Results}

\section{Long-access self-administration leads to escalated oxycodone intake in rats}


Figure 1 shows the experimental timeline and behavioral results for oxycodone SA. As described in details under methods, rats were given short-access (ShA) or long-access $(\mathrm{LgA})$ to oxycodone during the experiment ${ }^{19}$. The repeated-measures ANOVA for reward earned included the between-subject factor, groups (Saline, ShA, LgA), the within-subject factor of SA days (training days 1-20), and the group $\times$ day interaction. This analysis showed statistically significant effects of group $\left[F_{(2,890)}=307.5, p<0.001\right]$, day $\left[F_{(19,890)}=3.016, p<0.0001\right]$, and significant group $\times$ day interaction $\left[F_{(38,890)}=\right.$ 3.958, $p<0.0001]$. A comparison of the LgA rats to Saline rats showed that the LgA rats increased their oxycodone intake substantially after training day 5 compared to Saline rats $\left[F_{(1,507)}=35, p<0.0001\right.$; Fig. $\left.1 B\right]$, with there being significant increases in the number of active lever presses $\left[F_{(1,507)}=87, p<0.0001\right.$; Fig. $\left.1 C\right]$ by $L g A$ rats during the drug SA experiments. As previously reported ${ }^{19}, \mathrm{LgA}$ rats could be further divided into two SA phenotypes depending on whether they took high ( $\mathrm{LgA}-\mathrm{H})$ and lower $(\mathrm{LgA}-\mathrm{L})$ amounts of oxycodone (Fig. 1D). Figure $1 \mathrm{E}$ shows that the $\mathrm{LgA}-\mathrm{H}$ rats consumed significantly more oxycodone than the ShA and $\operatorname{LgA}-\operatorname{L}$ rats $\left[F_{(2,29)}=85.00, p<0.0001\right]$.

\section{Effects of early withdrawal and oxycodone SA on the activation of PKC}

Rats were euthanized 2 hours after cessation of oxycodone SA and their dorsal striata were used in Western Blot analyses of several phospho-proteins involved in the MAPK/MSK signaling pathway. The kinase, PKC, is known to be involved in the MAPK signaling cascade stimulated by opioid receptors ${ }^{28-30}$. Supplementary Figure S1 shows the effects of oxycodone SA on PKC and PPKC protein expression in the dorsal striata of rats euthanized at $2 \mathrm{~h}$ after cessation of drug SA. There were no significant changes in striatal PKC protein levels $\left[F_{(3,18)}=0.73, p=0.540\right.$; Supplementary Fig. S1]. However, changes in phosphorylated PKC (pPKC) abundance trended towards significance $\left[\mathrm{F}_{(3,18)}\right.$ 
$=2.82, p=0.068]$ in LgA-H rats, with planned tests showing small increases in LgA-H in comparison to Saline and ShA rats (Supplementary Fig. S1). Importantly, pPKC/PKC ratios were significantly increased $\left[F_{(3,18)}=4.45, p=0.0165\right]$ in the LgA-H group compared to the other groups (Supplementary Fig. S1). Regression analysis revealed a significant positive correlation between $\mathrm{pPKC/PKC}$ ratios and the amount of total oxycodone taken during the SA experiment (Supplementary Fig. S1). By contrast, there were no changes in protein kinase $A(P K A)$ protein expression $\left[F_{(3,20)}=1.98, p=0.1498\right]$ or pPKA abundance $\left[F_{(3,20)}=2.22, p=0.1178\right]$ (Supplementary Fig. S2), suggesting that changes in the PKA signaling pathway were not involved in oxycodone SA after 20 days of drug exposure in a manner consistent with a previous report that cAMP/PKA cascade might not be involved in the rewarding properties of morphine ${ }^{31}$.

\section{Withdrawal from oxycodone SA increases ERK phosphorylation in LgA rats}

ERK1/2 are members of MAPK kinases that are regulated by opioid drugs ${ }^{32}$ and are also activated by PKC ${ }^{33}$. We thus measured their expression in oxycodone-exposed rats and found no significant changes $\left[F_{(3,20)}=2.18, p=0.1224\right]$ in striatal ERK1/2 protein expression (Figs. 2A, 2B). However, there were increases $\left[F_{(3,20)}=6.41, p=\right.$ 0.0032] in the abundance of pERK1/2 in the LgA-H group in comparison to Saline and ShA groups (Figs. 2A, 2C). pERK/ERK ratios were also significantly increased $\left[F_{(3,20)}=\right.$ 7.10, $\mathrm{p}=0.0020]$ in the LgA-H group in comparison to the other 3 groups (Fig. 2D). Regression analysis showed oxycodone amount-dependent increases in pERK/ERK ratios (Fig. 2E).

\section{Effects of oxycodone and early withdrawal on MSK1 and MSK2 proteins}


ERK1/2 kinases phosphorylate MSK1 and MSK2 proteins in the MAPK/MSK cascade ${ }^{34,35}$. MSK1 is also activated in neurons in response to stress and neurotrophins ${ }^{36}$. We therefore tested the possibility that MSK1 and MSK2 phosphorylation might be affected in oxycodone SA animals. Figure 3 shows the effects of oxycodone SA on MSK1, pMSK1, MSK2, and pMSK2 levels. MSK1 protein expression was significantly decreased $\left[F_{(3,20)}=6.18, p=0.0038\right]$ in both $\mathrm{LgA}-\mathrm{L}$ and $\mathrm{LgA}-\mathrm{H}$ rats in comparison to the Saline group (Figs. 3A, 3B). However, pMSK1 abundance was substantially increased $\left[\mathrm{F}_{(3,20)}=4.53, \mathrm{p}=0.0140\right]$ in the $\mathrm{LgA}-\mathrm{H}$ group in comparison to Sal and ShA groups

(Figs. 3A, 3C). In addition, pMSK1/MSK ratios were increased $\left[F_{(3,20)}=16.3, p<0.0001\right]$ in both LgA-L and LgA-H rats in comparison to Sal and ShA animals (Fig. 3D). Regression analysis revealed significant correlation between pMSK1/MSK ratios and amount of oxycodone self-administered (Fig. 3E).

There were no significant changes $\left[F_{(3,19)}=1.52, p=0.2413\right]$ in MSK2 protein expression (Figs. 3F, 3G). There were, however, significant increases $\left[F_{(3,20)}=8.73, p=\right.$ 0.0007] in pMSK2 abundance only in LgA-H rats in comparison to other groups (Figs. 3F, $3 \mathrm{H})$. pMSK2/MSK2 ratios were also significantly increased $\left[F_{(3,20)}=6.50, p=0.0030\right]$ in only LgA-H rats (Fig. 3l), with significant positive correlation observed between these ratios and amount of oxycodone taken during the SA experiment (Fig. 3J).

\section{Increased pCREB in LgA-H rats}

Because CREB phosphorylation can be mediated by several upstream kinases that include PKC, ERK1/2 and MSKs ${ }^{37}$, we examined the possibility that activation of these kinases might have led to increased PCREB after oxycodone SA. There were no significant changes $[F(3,18)=2.97, p=0.0592]$ in CREB protein expression (Figs. 4A, 4B). However, the abundance of pCREB was significantly increased $[F(3,20)=5.71, p=$ 
0.0054] in LgA-L and LgA-H groups in comparison to the Saline group (Figs. 4A, 4C). Furthermore, pCREB/CREB ratios were also substantially increased $\left[F_{(3,20)}=3.93, p=\right.$ 0.0235] in the LgA-H group compared to other groups (Fig. 4D), with there being a significant positive correlation between these ratios and amount of oxycodone taken (Fig. 4E).

\section{Oxycodone SA induces increased phosphoacetylation in LgA rats}

In addition to CREB phosphorylation, activated MSK1 and MSK2 participate in the phosphorylation of $\mathrm{H} 3$ at serine residue $\mathrm{S} 10$ and can cause increases in $\mathrm{H} 3$ phosphoacetylation of H3S10pK14Ac ${ }^{34,37,38}$. We therefore sought to determine the effects of oxycodone SA on the abundance of this histone marker. Figure 5 shows the results for $\mathrm{H} 3$ and $\mathrm{H} 3 \mathrm{~S} 10 \mathrm{pK} 14 \mathrm{Ac}$. Unexpectedly, we found significant decreases $\left[\mathrm{F}_{(3,20)}\right.$ $=5.02, p=0.0094]$ in $\mathrm{H} 3$ protein levels in the ShA group in comparison with Sal and the LgA-H groups (Figs. 5A, 5B). In contrast, H3S10pK14Ac abundance was significantly increased $\left[F_{(3,20)}=20.0, p<0.0001\right]$ in the $\mathrm{LgA}-\mathrm{L}$ and $\mathrm{LgA}-\mathrm{H}$ groups compared with Saline rats. Moreover, H3S10pK14Ac in the LgA-H group was substantially increased compared to the other 3 groups (Figs. 5A, 5C). H3S10pK14Ac/H3 ratios were also increased $\left[F_{(3,20)}=20.0, p<0.0001\right]$ in the LgA-L and LgA-H groups compared to the Saline and ShA groups (Fig. 5D). Regression analyses revealed that both $\mathrm{H} 3 \mathrm{~S} 10 \mathrm{pK} 14 \mathrm{Ac}$ abundance and $\mathrm{H} 3 \mathrm{~S} 10 \mathrm{pK} 14 \mathrm{Ac} / \mathrm{H} 3$ ratios positively correlated with the amount of total oxycodone taken during the experiment (Figs. 5E, 5F).

\section{Differential protein expression of CBP and H3K27Ac in oxycodone exposed rats}


Phosphorylated CREB recruits CBP, under certain circumstances, to promote changes in gene expression ${ }^{39,40}$. We thus tested the possibility that oxycodone SA might have influenced striatal CBP protein expression and found that CBP protein expression was significantly increased $\left[F_{(3,17)}=6.82, p=0.0032\right]$ in the LgA-L and LgA-H rats compared with the Saline and ShA groups (Figs. 6A, 6B). Increased CBP expression correlated with the amount of oxycodone consumed by the rats (Fig. 6C).

In addition to CBP's transcriptional co-activity, it functions as a histone acetyltransferase $^{41,42}$ that mediates acetylation of $\mathrm{H} 3 \mathrm{~K} 27^{43-45}$, a marker of active enhancers ${ }^{46-48}$ that is involved in regulating neuronal gene expression. We therefore measured the abundance of H3K27Ac, which had been previously shown to be impacted in the brains of heroin addicts ${ }^{49}$. We found significant increases $\left[F_{(3,20)}=4.53\right.$, $p=0.0140]$ in H3K27Ac abundance in all oxycodone groups, including ShA rats that did not escalate their intake (Figure 6D, 6E), suggesting that oxycodone exposure is enough to increase striatal H3K27Ac abundance. We found that H3K27Ac abundance positively correlated with the amount of oxycodone self-administered by rats (Fig. 6F). These increases confirm the data in heroin-using individuals ${ }^{49}$. $\mathrm{H} 3 \mathrm{~K} 27 \mathrm{Ac} / \mathrm{H} 3$ ratios were also significantly increased $\left[F_{(3,20)}=3.82, p=0.0259\right]$ in the 3 oxycodone groups (Fig. $6 \mathrm{G}$ ) and correlated with the amount of oxycodone taken (Fig. 6H).

Because CBP expression was only increased in the two LgA groups while H3K27Ac was increased in the 3 oxycodone groups, we sought to determine if the expression of another histone $\mathrm{H} 3$ acetyltransferase, Tip60, with putative activity towards the lysine 27 residue ${ }^{50}$ was affected in the 3 oxycodone groups. Indeed, Tip60 protein expression was significantly increased $\left[F_{(3,20)}=3.63, p=0.0307\right]$ in all three oxycodone groups (Supplementary Fig. S4). 


\section{Oxycodone SA increases GluA2 and GluA3 glutamate receptor mRNA levels}

Changes in gene expression in response to exogenous stimuli include many target genes that are expressed with different time courses of induction. Because respective changes in histone phosphorylation and acetylation generated by MSKs and CBP are known regulators of gene expression ${ }^{51-54}$, we tested the idea that some of their target genes might be affected in the striata of oxycodone-exposed rats. We also measured the mRNA levels of some glutamatergic genes whose expression was altered in the brains of heroin users based on a previous microarray study ${ }^{49}$. Figure 7 shows the effects of oxycodone SA on the mRNA expression of GluA1, GluA2, GluA3, and GluA4 subunits of AMPA receptors ${ }^{55}$. We found no substantial changes in $\operatorname{GluA1}\left[\mathrm{F}_{(3,29)}=2.03, \mathrm{p}=\right.$ 0.1322; Fig. 7A] and GluA4 $\left[\mathrm{F}_{(3,34)}=1.60, p=0.2084 ;\right.$ Fig. $\left.7 \mathrm{G}\right] \mathrm{mRNA}$ levels, with no relationships between their levels and the amount of oxycodone consumed during the experiment (Figs. 7B, 7H). In contrast, striatal GluA2 $\left[F_{(3,27)}=3.49, p=0.0291\right.$; Fig. $\left.7 \mathrm{C}\right]$ and GluA3 $\left[F_{(3,31)}=15.7, p<0.0001 ;\right.$ Fig. $\left.7 \mathrm{E}\right]$ were increased in the LgA-H group compared to other groups. Regression analyses revealed significant oxycodone amountdependent changes in their mRNA levels (Figs. 7D, 7F). Moreover, the changes in GluA2 and GluA3 mRNAs correlated with changes in pMSK1 (Figs. 8A, 8B). However, only changes in GluA3, but not in GluA2, mRNA levels correlated with changes in pMSK2, H3S10pK14Ac, and CBP protein expression (Figs. 8C-8H).

mRNA levels of acetyltransferases, Ncoa1-3, are increased in LgA oxycodone rats

Egervari et al. (2017) had recently reported that the expression of the acetyltransferase, nuclear receptor coactivator 1 (Ncoa1), was significantly increased in the ventral striatum 
of heroin users. We therefore measured the expression of Ncoa1-3 in our experiment.

Supplemental Figure 3 shows significant increases in the mRNA levels of $\operatorname{Ncoa} 1\left[F_{(3,35)}\right.$

$=12.6 ; p<0.0001], \operatorname{Ncoa} 2\left[F_{(3,31)}=4.55 ; p=0.0094\right]$, and Ncoa3 $\left[F_{(3,28)}=12.5 ; p<\right.$

0.0001] in the LgA-H group compared to the other groups. Furthermore, there were

significant correlations between their expression and changes in pMSK1, pMSK2, and

H3S10pK14Ac protein abundance (Supplementary Fig. S3). However, we observed no significant correlations between Ncoa1, Ncoa2, and Ncoa3 mRNA levels and CBP suggesting that histone phosphorylation might play a more important role in regulating their expression than histone acetylation (Supplementary Fig. S3).

\section{Discussion}

In the present study, we show that long-access to oxycodone SA over a period of 20 days leads to activation of several kinases involved in the MAPK/MSK signaling pathway with consequent CREB and histone $\mathrm{H} 3$ phosphorylation in the rat dorsal striatum. These results are consistent, in part, with previous evidence of the involvement of the MAPK in the biochemical effects of morphine ${ }^{56,57}$. We also found significant increases in CBP and H3K27 acetylation in oxycodone-exposed rats. These findings are consistent with observations that epigenetic mechanisms are involved in models of opioid abuse ${ }^{58}$. The changes in signaling pathways are accompanied by oxycodone-induced increased gene expression of GluA2 and GluA3 subunits of AMPA receptors and of the acetyltransferases, Ncoa1-3. Our results provide novel insights into the role of H3S10pK14Ac in oxycodone-induced gene expression and hint to a model whereby this histone marker is involved in the regulation of genes that might be responsible for some long-term molecular adaptations that drive compulsive oxycodone intake. 
The dorsal striatum is a brain region that is integral to various behavioral changes consequent to drug taking behaviors including habit forming and drug seeking during periods of opioid withdrawal ${ }^{19,22,23,59}$. Similar to other observations with cocaine, methamphetamine, and other drugs ${ }^{58,60-66}$, we found increased phosphorylation of PKC, ERK1/2, MSK1/2, and pCREB in the rat dorsal striatum after repeated exposure to oxycodone SA. Increased phosphorylation of H3S10pK14Ac, a marker that is downstream of these kinases ${ }^{34,37,67}$ is of interest because these findings suggest that repeated exposure to long-access oxycodone self-administration might engender a permissive molecular state characterized by increased histone $\mathrm{H} 3$ phosphoacetylation and a more open chromatin structure. The hypothesized permissive state might also facilitate pCREB binding at the cAMP-Response Element (CRE) on the promoters of genes that have been implicated in the regulation of synaptic plasticity ${ }^{51,68,69}$. CREB activation is also known to enhance the recruitment of co-activators ${ }^{39,40}$ such as CBP, an acetyltransferase that acetylates $\mathrm{H} 3 \mathrm{~K} 27^{43-45,70}$ to increase the transcription of downstream genes in diverse cell populations ${ }^{39,71,72}$. This suggestion is further supported by observations of increased expression of co-activators for the steroid hormone receptor family, Ncoa ${ }^{73}, \mathrm{Ncoa} 2^{74}$, and $\mathrm{Ncoa} 3^{75}$, that can enhance transcription, in part, via histone acetylation ${ }^{76,77}$ and recruitment of $C B P{ }^{75,78,79}$, whose expression is also increased in rats exposed to relatively large quantities of oxycodone. Our proposal of an oxycodone-induced permissive state in the dorsal striatum is consistent with observations that histone $\mathrm{H} 3$ phosphorylation and acetylation can work in concert to regulate gene expression ${ }^{80}$. This discussion is supported by the observations that H3 phosphoacetylation also participates in heroin-induced conditioned place preference ${ }^{81}$, thus indicating a role of phosphoacetylation in the effects of opioids in general. 
Our observations of increased $\mathrm{H} 3$ phosphorylation and acetylation led us to test the possibility that some genes downstream of these molecular events might show differential expression in the brains of oxycodone-exposed rats. Indeed, we found increased expression of several genes in the $\mathrm{LgA}-\mathrm{H}$ rats that showed increased abundance of striatal pMSK1, pMSK2, and histone H3S10pK14Ac. Of interest among those are the changes in AMPA receptor subunits, GluA2 and GluA3, in LgA-H rats in an oxycodone amount- and pMSK1-dependent fashion. MSK1 and MSK2 are known to play substantial roles in a number of biological events including synaptic plasticity ${ }^{82}$. The altered expression of GluA2 and GluA3 is of singular interest because Egervari et al. (2017) had reported that their microarray analyses, using tissues from the ventral striatum of heroin users, had detected changes in the expression of several genes, including GluA3, which are involved in glutamate neurotransmission. Increases in the expression of GluA2 and GluA3 receptor subunits in our study are consistent with the ${ }^{83,84}$ proposed roles of glutamate receptors in substance use disorder includes cocaine ${ }^{85}$, methamphetamine ${ }^{86}$, and opioids ${ }^{83,84}$. For example, chronic cocaine increases G/uA2 expression in the nucleus accumbens and increased expression of GluA2 via viral injections enhanced the sensitivity of mice to the behavioral effects of cocaine ${ }^{85}$, thus suggesting that increased GluA2 expression in the present study might have served to facilitate escalation of oxycodone intake in the $\mathrm{LgA}-\mathrm{H}$ rats. A similar argument could be made for our novel findings of increased GluA3 expression after oxycodone SA. GluA3containing AMPA receptors are located in various brain regions ${ }^{87,88}$. Because GluA3 exists in GluA2A3 combinations or GluA3 monomers or dimers ${ }^{89}$, it is possible that increased expression of both GluA2 and GluA3 might potentiate AMPAR-mediated changes in synaptic plasticity during repeated oxycodone exposure. Alternatively, GluA3 alone may regulate oxycodone intake because GluA3 knockout mice show decreased 
alcohol intake ${ }^{90}$. Thus, elucidation of the specific roles that GluA3 alone or in combination with GluA2 play in oxycodone SA will await future genetic and pharmacological studies.

In conclusion, we have demonstrated that rats that self-administer large quantities of oxycodone showed increased histone and CREB phosphorylation via activation of the MAPK/MSK phosphorylation signaling pathway in the rat dorsal striatum. Rats exposed to large quantities of oxycodone also showed increased striatal CBP and histone acetylation in oxycodone-exposed rats. Changes in histone modifications are proposed to lead to more permissive chromatin states that promoted changes in the expression in a diversity of classes of genes as exemplified by increased mRNA levels of acetyltransferases, Ncoa1-3, and of AMPA receptor subunits, GluA2 and GluA3, in an oxycodone amount-dependent fashion. Importantly, changes in the expression of both GluA2 and GluA3 mRNA levels correlated with altered abundance of pMSK1, a kinase that is involved in the regulation of synaptic plasticity ${ }^{91}$. These suggestions are illustrated schematically in Figure 9. Finally, involvement of MAPK/MSK/histone phosphorylation in oxycodone SA identifies these kinases as potential pharmacological targets against oxycodone use disorder.

\section{Conflict of interest statement}

All authors report no financial interests or potential conflicts of interest.

\section{Author contributions}

C.A.B, M.T.M, and B.L performed self-administration, western blot and RT-qPCR experiments. C.A.B and J.L.C prepared manuscript. J.L.C supervised the overall project. 
bioRxiv preprint doi: https://doi org/10.1101/2020.08.31.276253; this version posted September 2, 2020. The copyright holder for this preprint (which was not certified by peer review) is the author/funder. This article is a US Government work. It is not subject to copyright under 17 USC 105 and is also made available for use under a CCO license.

\section{Funding}

This work was supported by funds of the Intramural Research Program of the DHHS/NIH/NIDA. 


\section{References}

1 Cicero, T. J., Inciardi, J. A. \& Munoz, A. Trends in abuse of Oxycontin and other opioid analgesics in the United States: 2002-2004. J Pain 6, 662-672, doi:10.1016/j.jpain.2005.05.004 (2005).

$2 \quad$ Skolnick, P. The Opioid Epidemic: Crisis and Solutions. Annu Rev Pharmacol Toxicol, doi:10.1146/annurev-pharmtox-010617-052534 (2017).

3 Balyan, R., Hahn, D., Huang, H. \& Chidambaran, V. Pharmacokinetic and pharmacodynamic considerations in developing a response to the opioid epidemic. Expert Opin Drug Metab Toxicol 16, 125-141, doi:10.1080/17425255.2020.1721458 (2020).

4 Gaskell, H., Derry, S., Stannard, C. \& Moore, R. A. Oxycodone for neuropathic pain in adults. Cochrane Database Syst Rev 7, CD010692, doi:10.1002/14651858.CD010692.pub3 (2016).

5 Schmidt-Hansen, M., Bennett, M. I., Arnold, S., Bromham, N. \& Hilgart, J. S. Oxycodone for cancer-related pain. Cochrane Database Syst Rev 8, CD003870, doi:10.1002/14651858.CD003870.pub6 (2017).

6 Van Zee, A. The promotion and marketing of oxycontin: commercial triumph, public health tragedy. Am J Public Health 99, 221-227, doi:10.2105/AJPH.2007.131714 (2009).

7 Rudd, R. A., Seth, P., David, F. \& Scholl, L. Increases in Drug and OpioidInvolved Overdose Deaths - United States, 2010-2015. MMWR Morb Mortal Wkly Rep 65, 1445-1452, doi:10.15585/mmwr.mm655051e1 (2016).

8 Seth, P., Scholl, L., Rudd, R. A. \& Bacon, S. Overdose Deaths Involving Opioids, Cocaine, and Psychostimulants - United States, 2015-2016. MMWR Morb Mortal Wkly Rep 67, 349-358, doi:10.15585/mmwr.mm6712a1 (2018).

9 Schuckit, M. A. Treatment of Opioid-Use Disorders. The New England journal of medicine 375, 357-368, doi:10.1056/NEJMra1604339 (2016).

10 Cadet, J. L. \& Bisagno, V. Neuropsychological Consequences of Chronic Drug Use: Relevance to Treatment Approaches. Front Psychiatry 6, 189, doi:10.3389/fpsyt.2015.00189 (2015).

11 Cadet, J. L., Bisagno, V. \& Milroy, C. M. Neuropathology of substance use disorders. Acta Neuropathol 127, 91-107, doi:10.1007/s00401-013-1221-7 (2014).

12 Noble, F., Lenoir, M. \& Marie, N. The opioid receptors as targets for drug abuse medication. Br J Pharmacol 172, 3964-3979, doi:10.1111/bph.13190 (2015).

13 Stein, C. Opioid Receptors. Annu Rev Med 67, 433-451, doi:10.1146/annurevmed-062613-093100 (2016).

14 Ehrich, J. M. et al. Kappa Opioid Receptor-Induced Aversion Requires p38 MAPK Activation in VTA Dopamine Neurons. J Neurosci 35, 12917-12931, doi:10.1523/JNEUROSCI.2444-15.2015 (2015).

15 Schulz, R., Eisinger, D. A. \& Wehmeyer, A. Opioid control of MAP kinase cascade. Eur J Pharmacol 500, 487-497, doi:10.1016/j.ejphar.2004.07.010 (2004).

16 Wagley, Y., Law, P. Y., Wei, L. N. \& Loh, H. H. Epigenetic Activation of muOpioid Receptor Gene via Increased Expression and Function of Mitogen- and Stress-Activated Protein Kinase 1. Mol Pharmacol 91, 357-372, doi:10.1124/mol.116.106567 (2017). 
17 Al-Hasani, R. \& Bruchas, M. R. Molecular mechanisms of opioid receptordependent signaling and behavior. Anesthesiology 115, 1363-1381, doi:10.1097/ALN.0b013e318238bba6 (2011).

18 Bruchas, M. R. \& Roth, B. L. New Technologies for Elucidating Opioid Receptor Function. Trends Pharmacol Sci 37, 279-289, doi:10.1016/j.tips.2016.01.001 (2016).

19 Blackwood, C. A. et al. Molecular Adaptations in the Rat Dorsal Striatum and Hippocampus Following Abstinence-Induced Incubation of Drug Seeking After Escalated Oxycodone Self-Administration. Mol Neurobiol 56, 3603-3615, doi:10.1007/s12035-018-1318-z (2019).

20 Blackwood, C. A., Leary, M., Salisbury, A., McCoy, M. T. \& Cadet, J. L. Escalated Oxycodone Self-Administration Causes Differential Striatal mRNA Expression of FGFs and IEGs Following Abstinence-Associated Incubation of Oxycodone Craving. Neuroscience 415, 173-183, doi:10.1016/j.neuroscience.2019.07.030 (2019).

21 Belin, D. \& Everitt, B. J. Cocaine seeking habits depend upon dopaminedependent serial connectivity linking the ventral with the dorsal striatum. Neuron 57, 432-441, doi:10.1016/j.neuron.2007.12.019 (2008).

22 Everitt, B. J. \& Robbins, T. W. Drug Addiction: Updating Actions to Habits to Compulsions Ten Years On. Annu Rev Psychol 67, 23-50, doi:10.1146/annurevpsych-122414-033457 (2016).

23 Hodebourg, R. et al. Heroin seeking becomes dependent on dorsal striatal dopaminergic mechanisms and can be decreased by $\mathrm{N}$-acetylcysteine. Eur $\mathrm{J}$ Neurosci, doi:10.1111/ejn.13894 (2018).

24 Cadet, J. L. et al. Genome-wide DNA hydroxymethylation identifies potassium channels in the nucleus accumbens as discriminators of methamphetamine addiction and abstinence. Mol Psychiatry 22, 1196-1204, doi:10.1038/mp.2016.48 (2017).

25 Wade, C. L., Vendruscolo, L. F., Schlosburg, J. E., Hernandez, D. O. \& Koob, G. F. Compulsive-like responding for opioid analgesics in rats with extended access. Neuropsychopharmacology 40, 421-428, doi:10.1038/npp.2014.188 (2015).

26 Blackwood, C. A., McCoy, M. T., Ladenheim, B. \& Cadet, J. L. Escalated Oxycodone Self-Administration and Punishment: Differential Expression of Opioid Receptors and Immediate Early Genes in the Rat Dorsal Striatum and Prefrontal Cortex. Front Neurosci 13, 1392, doi:10.3389/fnins.2019.01392 (2019).

27 Paxinos, G. a. W., C. The rat brain in stereotaxic coordinates, 6th Edn. Burlington, MA: Academic Press. (1998).

28 Kramer, H. K. \& Simon, E. J. Role of protein kinase C (PKC) in agonist-induced mu-opioid receptor down-regulation: I. PKC translocation to the membrane of $\mathrm{SH}-\mathrm{SY} 5 \mathrm{Y}$ neuroblastoma cells is induced by mu-opioid agonists. J Neurochem 72, 585-593, doi:10.1046/j.1471-4159.1999.0720585.x (1999).

29 Kramer, H. K. \& Simon, E. J. Role of protein kinase C (PKC) in agonist-induced mu-opioid receptor down-regulation: II. Activation and involvement of the alpha, epsilon, and zeta isoforms of PKC. J Neurochem 72, 594-604, doi:10.1046/j.1471-4159.1999.0720594.x (1999).

30 Williams, J. T. et al. Regulation of mu-opioid receptors: desensitization, phosphorylation, internalization, and tolerance. Pharmacol Rev 65, 223-254, doi:10.1124/pr.112.005942 (2013).

31 Borgkvist, A., Usiello, A., Greengard, P. \& Fisone, G. Activation of the cAMP/PKA/DARPP-32 signaling pathway is required for morphine psychomotor 
stimulation but not for morphine reward. Neuropsychopharmacology 32, 19952003, doi:10.1038/sj.npp.1301321 (2007).

32 Ortiz, J. et al. Extracellular signal-regulated protein kinases (ERKs) and ERK kinase (MEK) in brain: regional distribution and regulation by chronic morphine. $J$ Neurosci 15, 1285-1297 (1995).

33 Tang, J. M. et al. Acetylcholine induces mesenchymal stem cell migration via Ca2+ /PKC/ERK1/2 signal pathway. J Cell Biochem 113, 2704-2713, doi:10.1002/jcb.24148 (2012).

34 Adewumi, I., Lopez, C. \& Davie, J. R. Mitogen and stress- activated protein kinase regulated gene expression in cancer cells. Adv Biol Regul 71, 147-155, doi:10.1016/j.jbior.2018.09.010 (2019).

35 Wiggin, G. R. et al. MSK1 and MSK2 are required for the mitogen- and stressinduced phosphorylation of CREB and ATF1 in fibroblasts. Mol Cell Biol 22, 2871-2881, doi:10.1128/mcb.22.8.2871-2881.2002 (2002).

36 Arthur, J. S. et al. Mitogen- and stress-activated protein kinase 1 mediates cAMP response element-binding protein phosphorylation and activation by neurotrophins. J Neurosci 24, 4324-4332, doi:10.1523/JNEUROSCI.522703.2004 (2004).

37 Deak, M., Clifton, A. D., Lucocq, L. M. \& Alessi, D. R. Mitogen- and stressactivated protein kinase-1 (MSK1) is directly activated by MAPK and SAPK2/p38, and may mediate activation of CREB. EMBO J 17, 4426-4441, doi:10.1093/emboj/17.15.4426 (1998).

38 Dyson, M. H. et al. MAP kinase-mediated phosphorylation of distinct pools of histone $\mathrm{H} 3$ at S10 or S28 via mitogen- and stress-activated kinase 1/2. J Cell Sci 118, 2247-2259, doi:10.1242/jcs.02373 (2005).

39 Cardinaux, J. R. et al. Recruitment of CREB binding protein is sufficient for CREB-mediated gene activation. Mol Cell Biol 20, 1546-1552, doi:10.1128/mcb.20.5.1546-1552.2000 (2000).

40 Kwok, R. P. et al. Nuclear protein CBP is a coactivator for the transcription factor CREB. Nature 370, 223-226, doi:10.1038/370223a0 (1994).

41 Ogryzko, V. V., Schiltz, R. L., Russanova, V., Howard, B. H. \& Nakatani, Y. The transcriptional coactivators p300 and CBP are histone acetyltransferases. Cell 87, 953-959, doi:10.1016/s0092-8674(00)82001-2 (1996).

42 Weinert, B. T. et al. Time-Resolved Analysis Reveals Rapid Dynamics and Broad Scope of the CBP/p300 Acetylome. Cell 174, 231-244 e212, doi:10.1016/j.cell.2018.04.033 (2018).

43 Jin, Q. et al. Distinct roles of GCN5/PCAF-mediated H3K9ac and CBP/p300mediated $\mathrm{H} 3 \mathrm{~K} 18 / 27 \mathrm{ac}$ in nuclear receptor transactivation. EMBO J 30, 249-262, doi:10.1038/emboj.2010.318 (2011).

44 Raisner, R. et al. Enhancer Activity Requires CBP/P300 BromodomainDependent Histone H3K27 Acetylation. Cell Rep 24, 1722-1729, doi:10.1016/j.celrep.2018.07.041 (2018).

45 Tie, F. et al. CBP-mediated acetylation of histone H3 lysine 27 antagonizes Drosophila Polycomb silencing. Development 136, 3131-3141, doi:10.1242/dev.037127 (2009).

46 Creyghton, M. P. et al. Histone H3K27ac separates active from poised enhancers and predicts developmental state. Proc Natl Acad Sci U S A 107, 21931-21936, doi:10.1073/pnas.1016071107 (2010).

$47 \mathrm{Kim}, \mathrm{T}$. K. et al. Widespread transcription at neuronal activity-regulated enhancers. Nature 465, 182-187, doi:10.1038/nature09033 (2010). 
48 Malik, A. N. et al. Genome-wide identification and characterization of functional neuronal activity-dependent enhancers. Nat Neurosci 17, 1330-1339, doi:10.1038/nn.3808 (2014).

49 Egervari, G. et al. Striatal H3K27 Acetylation Linked to Glutamatergic Gene Dysregulation in Human Heroin Abusers Holds Promise as Therapeutic Target. Biol Psychiatry 81, 585-594, doi:10.1016/j.biopsych.2016.09.015 (2017).

$50 \mathrm{Hsu}, \mathrm{C}$. C. et al. Recognition of histone acetylation by the GAS41 YEATS domain promotes H2A.Z deposition in non-small cell lung cancer. Genes Dev 32, 58-69, doi:10.1101/gad.303784.117 (2018).

51 Impey, S. et al. Defining the CREB regulon: a genome-wide analysis of transcription factor regulatory regions. Cell 119, 1041-1054, doi:10.1016/j.cell.2004.10.032 (2004).

52 Kasper, L. H., Qu, C., Obenauer, J. C., McGoldrick, D. J. \& Brindle, P. K. Genome-wide and single-cell analyses reveal a context dependent relationship between CBP recruitment and gene expression. Nucleic Acids Res 42, 1136311382, doi:10.1093/nar/gku827 (2014).

53 Ramos, Y. F. et al. Genome-wide assessment of differential roles for p300 and CBP in transcription regulation. Nucleic Acids Res 38, 5396-5408, doi:10.1093/nar/gkq184 (2010).

54 Wiersma, M. et al. Protein kinase Msk1 physically and functionally interacts with the KMT2A/MLL1 methyltransferase complex and contributes to the regulation of multiple target genes. Epigenetics Chromatin 9, 52, doi:10.1186/s13072-0160103-3 (2016).

55 Traynelis, S. F. et al. Glutamate receptor ion channels: structure, regulation, and function. Pharmacol Rev 62, 405-496, doi:10.1124/pr.109.002451 (2010).

56 Duraffourd, C., Kumala, E., Anselmi, L., Brecha, N. C. \& Sternini, C. Opioidinduced mitogen-activated protein kinase signaling in rat enteric neurons following chronic morphine treatment. PLoS One 9, e110230, doi:10.1371/journal.pone.0110230 (2014).

57 Jia, W. et al. Differential Regulation of MAPK Phosphorylation in the Dorsal Hippocampus in Response to Prolonged Morphine Withdrawal-Induced Depressive-Like Symptoms in Mice. PLoS One 8, e66111, doi:10.1371/journal.pone.0066111 (2013).

58 Browne, C. J., Godino, A., Salery, M. \& Nestler, E. J. Epigenetic Mechanisms of Opioid Addiction. Biol Psychiatry 87, 22-33, doi:10.1016/j.biopsych.2019.06.027 (2020).

59 Bossert, J. M. et al. Role of mu, but not delta or kappa, opioid receptors in context-induced reinstatement of oxycodone seeking. Eur J Neurosci, doi:10.1111/ejn.13955 (2018).

60 Brami-Cherrier, K., Roze, E., Girault, J. A., Betuing, S. \& Caboche, J. Role of the ERK/MSK1 signalling pathway in chromatin remodelling and brain responses to drugs of abuse. J Neurochem 108, 1323-1335, doi:10.1111/j.14714159.2009.05879.x (2009).

61 Garcia-Pardo, M. P., Roger-Sanchez, C., Rodriguez-Arias, M., Minarro, J. \& Aguilar, M. A. Pharmacological modulation of protein kinases as a new approach to treat addiction to cocaine and opiates. Eur J Pharmacol 781, 10-24, doi:10.1016/j.ejphar.2016.03.065 (2016).

62 Krasnova, I. N. et al. CREB phosphorylation regulates striatal transcriptional responses in the self-administration model of methamphetamine addiction in the rat. Neurobiol Dis 58, 132-143, doi:10.1016/j.nbd.2013.05.009 (2013). 
63 Mattson, B. J. et al. Cocaine-induced CREB phosphorylation in nucleus accumbens of cocaine-sensitized rats is enabled by enhanced activation of extracellular signal-related kinase, but not protein kinase A. J Neurochem 95, 1481-1494, doi:10.1111/j.1471-4159.2005.03500.x (2005).

64 Miller, B. W. et al. Cocaine craving during protracted withdrawal requires PKCepsilon priming within vmPFC. Addict Biol 22, 629-639, doi:10.1111/adb.12354 (2017).

65 Shin, E. J. et al. Significance of protein kinase C in the neuropsychotoxicity induced by methamphetamine-like psychostimulants. Neurochem Int 124, 162170, doi:10.1016/j.neuint.2019.01.014 (2019).

66 Torres, O. V., Jayanthi, S., McCoy, M. T. \& Cadet, J. L. Selective Activation of Striatal NGF-TrkA/p75NTR/MAPK Intracellular Signaling in Rats That Show Suppression of Methamphetamine Intake 30 Days following Drug Abstinence. Int J Neuropsychopharmacol 21, 281-290, doi:10.1093/ijnp/pyx105 (2018).

67 Chung, Y. W., Kim, H. K., Kim, I. Y., Yim, M. B. \& Chock, P. B. Dual function of protein kinase $\mathrm{C}$ (PKC) in 12-O-tetradecanoylphorbol-13-acetate (TPA)-induced manganese superoxide dismutase (MnSOD) expression: activation of CREB and FOXO3a by PKC-alpha phosphorylation and by PKC-mediated inactivation of Akt, respectively. J Biol Chem 286, 29681-29690, doi:10.1074/jbc.M111.264945 (2011).

68 Kandel, E. R. The molecular biology of memory: CAMP, PKA, CRE, CREB-1, CREB-2, and CPEB. Mol Brain 5, 14, doi:10.1186/1756-6606-5-14 (2012).

69 Lakhina, V. et al. Genome-wide functional analysis of CREB/long-term memorydependent transcription reveals distinct basal and memory gene expression programs. Neuron 85, 330-345, doi:10.1016/j.neuron.2014.12.029 (2015). Zhang, X. et al. Genome-wide analysis of cAMP-response element binding protein occupancy, phosphorylation, and target gene activation in human tissues. Proc Natl Acad Sci U S A 102, 4459-4464, doi:10.1073/pnas.0501076102 (2005).

71 Liu, Y. et al. Transcriptional landscape of the human cell cycle. Proc Natl Acad Sci U S A 114, 3473-3478, doi:10.1073/pnas.1617636114 (2017).

72 Paauw, N. D. et al. H3K27 acetylation and gene expression analysis reveals differences in placental chromatin activity in fetal growth restriction. Clin Epigenetics 10, 85, doi:10.1186/s13148-018-0508-x (2018).

73 Onate, S. A., Tsai, S. Y., Tsai, M. J. \& O'Malley, B. W. Sequence and characterization of a coactivator for the steroid hormone receptor superfamily. Science 270, 1354-1357, doi:10.1126/science.270.5240.1354 (1995).

74 Voegel, J. J., Heine, M. J., Zechel, C., Chambon, P. \& Gronemeyer, H. TIF2, a $160 \mathrm{kDa}$ transcriptional mediator for the ligand-dependent activation function AF2 of nuclear receptors. EMBO J 15, 3667-3675 (1996).

75 Torchia, J. et al. The transcriptional co-activator p/CIP binds CBP and mediates nuclear-receptor function. Nature 387, 677-684, doi:10.1038/42652 (1997).

76 Chen, $\mathrm{H}$. et al. Nuclear receptor coactivator ACTR is a novel histone acetyltransferase and forms a multimeric activation complex with P/CAF and CBP/p300. Cell 90, 569-580, doi:10.1016/s0092-8674(00)80516-4 (1997).

77 Spencer, T. E. et al. Steroid receptor coactivator-1 is a histone acetyltransferase. Nature 389, 194-198, doi:10.1038/38304 (1997).

78 Leo, C. \& Chen, J. D. The SRC family of nuclear receptor coactivators. Gene 245, 1-11, doi:10.1016/s0378-1119(00)00024-x (2000).

79 Olivares, A. M., Moreno-Ramos, O. A. \& Haider, N. B. Role of Nuclear Receptors in Central Nervous System Development and Associated Diseases. J Exp Neurosci 9, 93-121, doi:10.4137/JEN.S25480 (2015). 
80 Cheung, P. et al. Synergistic coupling of histone $\mathrm{H} 3$ phosphorylation and acetylation in response to epidermal growth factor stimulation. Mol Cell 5, 905915, doi:10.1016/s1097-2765(00)80256-7 (2000).

81 Sheng, J., Lv, Z., Wang, L., Zhou, Y. \& Hui, B. Histone H3 phosphoacetylation is critical for heroin-induced place preference. Neuroreport 22, 575-580, doi:10.1097/WNR.0b013e328348e6aa (2011).

82 Reyskens, K. M. \& Arthur, J. S. Emerging Roles of the Mitogen and Stress Activated Kinases MSK1 and MSK2. Front Cell Dev Biol 4, 56, doi:10.3389/fcell.2016.00056 (2016).

83 Billa, S. K. et al. Increased insertion of glutamate receptor 2-lacking alpha-amino3-hydroxy-5-methyl-4-isoxazole propionic acid (AMPA) receptors at hippocampal synapses upon repeated morphine administration. Mol Pharmacol 77, 874-883, doi:10.1124/mol.109.060301 (2010).

84 Zhang, Y. et al. Chronic Oxycodone Self-administration Altered Reward-related Genes in the Ventral and Dorsal Striatum of C57BL/6J Mice: An RNA-seq Analysis. Neuroscience 393, 333-349, doi:10.1016/j.neuroscience.2018.07.032 (2018).

85 Kelz, M. B. et al. Expression of the transcription factor deltaFosB in the brain controls sensitivity to cocaine. Nature 401, 272-276, doi:10.1038/45790 (1999).

86 Jayanthi, S. et al. Methamphetamine downregulates striatal glutamate receptors via diverse epigenetic mechanisms. Biol Psychiatry 76, 47-56, doi:10.1016/j.biopsych.2013.09.034 (2014).

87 Renner, M. C. et al. Synaptic plasticity through activation of GluA3-containing AMPA-receptors. Elife 6, doi:10.7554/eLife.25462 (2017).

88 Schwenk, J. et al. Regional diversity and developmental dynamics of the AMPAreceptor proteome in the mammalian brain. Neuron 84, 41-54, doi:10.1016/j.neuron.2014.08.044 (2014).

89 Reimers, J. M., Milovanovic, M. \& Wolf, M. E. Quantitative analysis of AMPA receptor subunit composition in addiction-related brain regions. Brain Res 1367, 223-233, doi:10.1016/j.brainres.2010.10.016 (2011).

90 Sanchis-Segura, C. et al. Involvement of the AMPA receptor GluR-C subunit in alcohol-seeking behavior and relapse. J Neurosci 26, 1231-1238, doi:10.1523/JNEUROSCI.4237-05.2006 (2006).

91 Correa, S. A. et al. MSK1 regulates homeostatic and experience-dependent synaptic plasticity. J Neurosci 32, 13039-13051, doi:10.1523/JNEUROSCI.093012.2012 (2012). 
Figure legends

Figure 1. Rats exposed to long-access, but not short-access, oxycodone SA escalate their drug intake. (A) Experimental timeline of oxycodone self-administration (SA) training. Rats self-administered oxycodone using either short-access (ShA) $(n=10)$ (trained for $3 \mathrm{~h}$ for 20 days) or long-access $(\operatorname{LgA})(n=21-23)$ (trained for $3 \mathrm{~h}$ for $1-5$ days, $6 \mathrm{~h}$ for $6-10$ days, then $9 \mathrm{~h}$ for 11-20 days) paradigms. (B) LgA rats escalate their intake of oxycodone after the first 5 days of SA training. (C) LgA rats show significant increases in active lever presses during SA training. (D) $\mathrm{LgA}-\mathrm{H}$ rats show two distinct intake phenotypes, high $(\operatorname{LgA}-\mathrm{H})(\mathrm{n}=10)$ and low $(\mathrm{LgA}-\mathrm{L})(\mathrm{n}=13)$ oxycodone takers, during the escalation phase. (E) LgA-H rats took substantially more oxycodone than $\mathrm{LgA}-\mathrm{L}$ and ShA rats. Key to statistics: ${ }^{*}{ }^{* *},{ }^{* * *}=p<0.05,0.01,0.001$, respectively, in comparison to Sal rats; \#, \#\#, \#\# = p < 0.05, 0.01, 0.001, respectively, in comparison to SHA rats; $\$ \$, \$ \$=p<0.01,0.001$ in comparison to LgA-L rats. Stats were performed by either one-way or two-way ANOVA followed by Bonferroni or Fisher's PLSD post hoc test.

Figure 2. Effects of oxycodone SA on ERK1/2 phosphorylation. (A) Images of western blot and $(\mathbf{B}, \mathbf{C})$ quantification of $E R K 1 / 2$, and $p E R K 1 / 2$. (B) ERK1/2 protein levels were not significantly impacted by oxycodone. (C) pERK1/2 abundance was increased in only $\mathrm{LgA}-\mathrm{H}$ rats. (D) $\mathrm{pERK} 1 / 2 / \mathrm{ERK} 1 / 2$ ratios are substantially increased in the LgA-H rats. (E) pERK1/2/ERK1/2 ratios correlate with amount of oxycodone taken $\left(n=6\right.$ Sal; $n=6$ ShA; $n=6$ LgA-L; $n=6$ LgA-H). Key to statistics: ${ }^{* *}=p<0.001$ in comparison to Sal rats; \#\#, \#\#\# = p < 0.01, 0.001, respectively, in comparison to ShA rats; $\$ \$=p<0.01$, in comparison to $L g A-L$ rats. Statistical analyses are as described in Figure 2. 
Figure 3. Increased MSK1 and MSK2 protein phosphorylation in LgA-H rats. (A, F) Images of western blot and (B, C, G, H) quantification of MSK1, pMSK1, MSK2, pMSK2. (B) MSK1 protein levels are decreased in LgA-L and LgA-H rats. (C) pMSK1 protein abundance is upregulated in $\mathrm{LgA}-\mathrm{L}$ and $\mathrm{LgA}-\mathrm{H}$ rats. (D) pMSK1/MSK1 ratios are increased in LgA rats; (E) Changes in pMSK1/MSK1 ratios are dependent on oxycodone intake. (G) MSK2 protein levels were not significantly affected by oxycodone. (H) pMSK2 abundance is increased in LgA-H rats. (I) pMSK2/MSK2 ratios are increased in LgA-H rats and $(J)$ correlated with amount of oxycodone ( $n=5-6$ Sal; $n=6$ ShA; $n=6$ LgA-L; $n=6$ LgA-H). Key to statistics: ${ }^{*},{ }^{* *},{ }^{* * *}=p<0.05,0.01,0.001$, respectively, in comparison to Sal rats; \#, \#\#, \#\# = p < 0.05, 0.01, 0.001, respectively, in comparison to SHA rats; $\$ \$=p<0.01$ in comparison to LgA-L rats. Statistical analyses are as described in Fig. 2 .

Figure 4. Increased phosphorylation of CREB protein levels in the LgA-H rats. (A) Images of western blot and $(\mathbf{B}, \mathbf{C})$ quantification of CREB and pCREB. (B) CREB protein levels show no significant changes. (C) pCREB is significantly increases in LgA-L and $\mathrm{LgA}-\mathrm{H}$ rats. (D) pCREB/CREB ratios are increased in the $\mathrm{LgA}-\mathrm{H}$ rats and (E) correlated with amount of oxycodone ( $n=5-6$ Sal; $n=6$ ShA; $n=5-6$ LgA-L; $n=6$ LgA-H). Key to statistics: ${ }^{*}{ }^{* *}=p<0.05,0.01$, respectively, in comparison to Sal rats; \#, \#\# =p<0.05, 0.01 , respectively, in comparison to SHA rats; $\$ \$=p<0.01$ in comparison to LgA-L rats. Statistical analyses are as described in Fig. 2.

\section{Figure 5. Effects of oxycodone SA and early withdrawal on H3 and H3S10pK14AC}

(A) Images of western blot and quantification of (B) H3 and (C) H3S10pK14Ac protein levels. (B) Protein levels of H3 display decrease in the ShA group. (C) Protein expression of H3S10pK14Ac shows significant increases in LgA-L and LgA-H groups. (D) Ratio of $\mathrm{H} 3 \mathrm{~S} 10 \mathrm{pK} 14 \mathrm{Ac} / \mathrm{H} 3$ displays significant increases in the $\mathrm{LgA}-\mathrm{L}$ and $\mathrm{LgA}-\mathrm{H}$ 
groups. (E) Protein expression of H3S10pK14Ac and (F) H3S10pK14Ac/H3 positively correlated with doses of oxycodone taken during the experiment $(n=5-6$ Sal; $n=6$ ShA; n=6 LgA-L; n=6 LgA-H). Key to statistics: ${ }^{*},{ }^{* *},{ }^{* * *}=p<0.05,0.01,0.001$, respectively, in comparison to Sal rats; \#, \#\#, \#\# = p < 0.05, 0.01, 0.001, respectively, in comparison to SHA rats; $\$ \$, \$ \$=p<0.01,0.001$ in comparison to LgA-L rats. Statistical analyses are as described in Fig. 2.

Figure 6. Differential effects on the protein expression of CBP and H3K27Ac after oxycodone SA. (A, D) Images of western blot and quantification of (B) CBP and (E) H3K27Ac protein levels. (B) CBP protein levels display significant increases in LgA groups. The protein levels of (E) H3K27Ac and (G) H3K27Ac/H3 protein were significantly increased in all drug groups. The regression analyses of (C) CBP, (F) H3K27Ac, and (H) H3K27Ac/H3 correlates with the amount of oxycodone taken $(n=5-6$ Sal; $n=5-6$ ShA; $n=6$ LgA-L; n=5-6 LgA-H). Key to statistics: * ${ }^{* *}=p<0.05,0.01$,

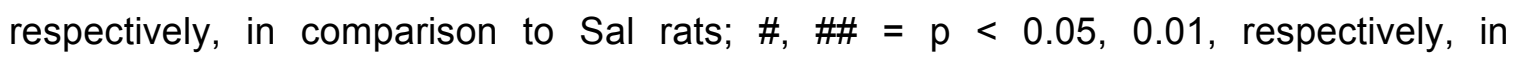
comparison to ShA rats. Statistical analyses are as described in Fig. 2.

Figure 7. Consequences of oxycodone SA and early withdrawal on mRNA on GluA1, GluA2, GluA3, and GluA4 mRNA levels. mRNA levels of (A) GluA1 and (G) GluA4 were not significantly affected. There were no correlations between (B) GluA1 and (H) GluA4 mRNA levels and the consumption of oxycodone. However, (C) GluA2 and (E) GluA3 mRNA levels were significantly increased in the LgA-H rats, with significant positive correlations between mRNA expression of (D) GluA2 and (F) GluA3 with the amount of oxycodone taken. Key to statistics: ${ }^{*}{ }^{* * *}=p<0.05,0.001$, respectively, in comparison to Sal rats; \#, \#\#\# = p < 0.05, 0.001, respectively, in comparison to SHA rats; $\$, \$ \$=p<0.05,0.001$ in comparison to LgA-L rats $(n=10-11$ 
Sal; $n=5-9$ ShA; n=4-7 LgA-L; $n=7-10$ LgA-H). Statistical analyses are as described in Fig. 2.

Figure 8. GIuA3 mRNA correlated with pMSK1, pMSK2, H3S10pK14Ac, and CBP protein expression. The mRNA expression of GluA2 shows significant linear relationship with (A) pMSK1, but not with (C) pMSK2, (E) H3S10pK14Ac, and (G) CBP protein expression. However, the mRNA levels of GluA3 display a positive correlation with the protein abundance of (B) pMSK1, (D) pMSK2, (F) H3S10pK14Ac, and (H) CBP $(n=5-6$ Sal; $n=5-6$ ShA; $n=5-6$ LgA-L; $n=5-6$ LgA-H). The correlation coefficients and $p$ values are shown on the graph.

Figure 9. Illustration of the activation of MAPK/MSK signaling pathway in LgA-H rats. Intake of large amount of oxycodone during long-access over 20 days caused increased phosphorylation of PKC, ERK1/2, MSK1, and MSK2. Increased MSK phosphorylation is accompanied by increased histone H3 phosphoacetylation and CREB phosphorylation. In addition, there were increases in the protein expression of two acetyltransferases, CBP and Tip60 that acetylate H3K27. Recruitment of CBP by CREB and histone modifications serve to create a permissible transcriptional environment that led to increased mRNA levels of GluA2 and GluA3 in a MSK1-dependent fashion. This kinase-histone modification cascade may serve as targets for therapeutic interventions against oxycodone use disorder.

Supplementary Figure 1. Effects of oxycodone SA on PKC phosphorylation. (A) Images of western blot and (B, C) quantification of PKC and PPKC. (B) PKC protein levels were not significantly affected in any group. (C) PPKC abundance is increased in only $\mathrm{LgA}-\mathrm{H}$ rats. (D) $\mathrm{pPKC/PKC}$ ratios are increased in only the $\mathrm{LgA}-\mathrm{H}$ rats. (E) $\mathrm{pPKC/PKC}$ ratios correlate with amount of oxycodone taken during the experiment $(\mathrm{n}=5$ - 
6 Sal; $n=6$ ShA; $n=5$ LgA-L; $n=6$ LgA-H). Key to statistics: * ${ }^{* *}=p<0.05,0.01$, respectively, in comparison to Sal rats; \#, \#\# = p < 0.05, 0.01, respectively, in comparison to ShA rats; $\$=p<0.05$ in comparison to $\mathrm{LgA}-\mathrm{L}$ rats. Statistical analyses were performed by one-way ANOVA followed by Bonferroni or Fisher's PLSD post hoc test. The correlation coefficients and $p$ values are shown on the graph.

Supplementary Figure 2. Exposure to oxycodone SA shows no changes in PKA. (A) Images of western blot and quantification of (B) PKA and (C) pPKA protein expression. Protein levels of (B-D) PKA, pPKA, and pPKA / PKA ratios show no significant changes. Similarly, (E) ratio of pPKA / PKA showed no correlation to the amount of oxycodone taken ( $n=6$ Sal; $n=6$ ShA; $n=6$ LgA-L; $n=6$ LgA-H). Statistical analyses were performed by one-way ANOVA followed by Bonferroni or Fisher's PLSD post hoc test. The correlation coefficients and $p$ values are shown on the graph.

Supplementary Figure 3. mRNA expression on the members of Ncoa family after exposure to oxycodone SA and early withdrawal. The mRNA levels of (A) Ncoa1, (B) Ncoa2, and (C) Ncoa3 show significant increases in the LgA-H group. The mRNA levels of Ncoa1, Ncoa2, and Ncoa3 show a positive correlation with (D-F) pMSK1, (G-I) pMSK2, and (J-L) H3S10pK14Ac. However, the mRNA expression of Ncoa1, Ncoa2, and Ncoa3 shows no correlation (M-O) CBP protein expression ( $n=4-9$ Sal; $n=5-9$ ShA; $\mathrm{n}=4-8$ LgA-L; $n=5-9$ LgA-H). Key to statistics: ${ }^{* *},{ }^{* * *}=p<0.01,0.001$, respectively, in comparison to Sal rats; \#, \#\#\# = p < 0.05, 0.001, respectively, in comparison to SHA rats; $\$ \$, \$ \$=p<0.01,0.001$, respectively, in comparison to $\mathrm{LgA}-\mathrm{L}$ rats. Statistical analyses are as described in Fig. 2.

Supplementary Figure 4. Exposure to oxycodone SA increases Tip60. (A) Images of western blot and (B) quantification of Tip60 protein levels show increases in all drug 
bioRxiv preprint doi: https://doi org/10.1101/2020.08.31.276253; this version posted September 2, 2020. The copyright holder for this preprint (which was not certified by peer review) is the author/funder. This article is a US Government work. It is not subject to copyright under 17 USC 105 and is also made available for use under a CCO license.

groups ( $n=5$ Sal; $n=6$ ShA; $n=6$ LgA-L; $n=6$ LgA-H). Key to statistics: * ${ }^{* *}=p<0.05,0.01$, respectively, in comparison to Sal rats. Stats were performed by one-way ANOVA followed by Bonferroni or Fisher's PLSD post hoc test. 
Supplementary Table 1. Antibody list

\begin{tabular}{|c|c|c|c|c|c|}
\hline Symbol & Source & Dilution & Catalog \# & RRID & Company \\
\hline PKC & Rabbit & $1: 1,000$ & 2056 & AB2284227 & Cell Signaling, Danvers, MA, USA \\
\hline pPKC & Mouse & $1: 1,000$ & SC-377565 & AB10611031 & Santa Cruz Bio. Tech., Dallas, TX, USA \\
\hline ERK1/2 & Rabbit & $1: 1,000$ & $06-182$ & AB310068 & Sigma-Aldrich, St. Louis, MO, USA \\
\hline $\mathrm{pERK} 1 / 2$ & Rabbit & $1: 1,000$ & 4370 & AB2315112 & Cell Signaling, Danvers, MA, USA \\
\hline MSK1 & Rabbit & $1: 1,000$ & 3489 & AB2285349 & Cell Signaling, Danvers, MA, USA \\
\hline pMSK1 & Rabbit & $1: 1,000$ & 9595 & AB2181783 & Cell Signaling, Danvers, MA, USA \\
\hline MSK2 & Rabbit & $1: 10,000$ & 3679 & AB2181641 & Cell Signaling, Danvers, MA, USA \\
\hline pMSK2 & Rabbit & $1: 10,000$ & SAB4504629 & AB11184854 & Sigma-Aldrich, St. Louis, MO, USA \\
\hline CREB & Rabbit & $1: 1,000$ & 9197 & AB331277 & Cell Signaling, Danvers, MA, USA \\
\hline pCREB & Mouse & $1: 1,000$ & 9196 & AB331275 & Cell Signaling, Danvers, MA, USA \\
\hline $\mathrm{H} 3$ & Rabbit & $1: 10,000$ & $06-755$ & AB2118461 & Sigma-Aldrich, St. Louis, MO, USA \\
\hline H3S10pK14Ac & Rabbit & $1: 1,000$ & $07-081$ & AB310366 & Sigma-Aldrich, St. Louis, MO, USA \\
\hline H3K27Ac & Rabbit & $1: 1,000$ & 39034 & AB2722569 & Active Motif, Carlsbad, CA, USA \\
\hline CBP & Rabbit & $1: 500$ & 7389 & aB2616020 & Cell Signaling, Danvers, MA, USA \\
\hline PKA & Mouse & $1: 1,000$ & 4782 & AB2170170 & Cell Signaling, Danvers, MA, USA \\
\hline pPKA & Rabbit & $1: 1,000$ & 5661 & AB10707163 & Cell Signaling, Danvers, MA, USA \\
\hline TIP60 & Rabbit & $1: 10,000$ & MABE430 & AB2551948 & Sigma-Aldrich, St. Louis, MO, USA \\
\hline CYPB & Rabbit & $1: 10,000$ & $a b 16045$ & AB443295 & Abcam, Cambridge, MA, USA \\
\hline Alpha-Tubulin & Mouse & $1: 25,000$ & T6074 & AB477582 & Sigma-Aldrich, St. Louis, MO, USA \\
\hline HRP (rabbit) & Goat & $1: 5,000$ & 7074 & AB2099233 & Cell Signaling, Danvers, MA, USA \\
\hline HRP (mouse) & Horse & $1: 5,000$ & 7076 & AB330924 & Cell Signaling, Danvers, MA, USA \\
\hline
\end{tabular}


Supplementary Table 2. List of RT-qPCR primers

\begin{tabular}{|l|l|l|}
\hline \multicolumn{1}{|c|}{ Gene Name } & \multicolumn{1}{|c|}{ Forward } & \multicolumn{1}{c|}{ Reverse } \\
\hline Aldh1a7 & CTT GGA TAG TGC TGT TGA GTT T & TTT CCT AGA ACG TAT TTC TTA GCC C \\
\hline Angp14 & AGC AAC TGT TCC AGA AGG & CAA TGA GCT GGG CCA TC \\
\hline Brd2 & CTC ATG TTC TCC AAC TGC TAT AA & CAA GGC AGT AGA GAC AGG TA \\
\hline Brd3 & CAC TCT GGA AAC ATC AGT TTG & TAA ACA TGG TGT TGA AGT CCT \\
\hline Cacna2d3 & GAT GAA TGG TCC TAC TGC AAC A & TCC AAT AGG CTT CGA TAG GG \\
\hline Dio2 & CTT GCT GAT CAC TCT TCA GAT T & TTA ACC TGT TTG TAG GCG TC \\
\hline Dusp14 & GGA TCC TTC GAA CGC TAG CTC & TCC TGG ACG TAC TCG CAA AC \\
\hline GluA1 & GGC AAA TAC GCC TAC C & ACT CGA TTA AGG CAA CC \\
\hline GluA2 & TCC TAC ACG GCT AAC TT & GCT CGA TGT ACT CGT TC \\
\hline Itpka & GTA GTA CAT TAG GAG CTG GC & GTA CAA TTC TGG ATC GGG AC \\
\hline Kcnc4 & CCT AAG ACA TGG TCA GGA AT & GTG GTA CAT GCT TCT TTC GTT \\
\hline Kcng1 & TGT TCC CAA ATG TGC CAC AA & CAG CAG TGT GAC GTA GTA AG \\
\hline Ncoa1 & GGT ACT TGT CCC TCT TCC CA & GTC CAG ACA CTG ACA TAG CA \\
\hline Ncoa2 & AGG AAG AAC TGA TGA ACA AGA G & CAT CCG ACA GTT GAA GGT ATG \\
\hline Ncoa3 & TGT ATC GTT TCT CAT TGG CTG & GAT TCG GGT TTG GTC TAC AT \\
\hline Nos1 & CCC AAG TTC GAC TGG TTT AAG & GTA TCG AGA GTT GTC ACA GTA G \\
\hline Pdgfd & CAA GGA TAA CTT CAA GAA CAA ACC A & AGA ACT TGT GAC TGA TTC CC \\
\hline Pdgfrl & CGG AAC AGA CAT TGT GTA CG & CGC TGG GAA CCT CTA CAT AA \\
\hline Pdk4 & GAT TAC TGA CCG CCT CTT TAG & ATG GAA TAG AGA TTC AGA TCT CCT \\
\hline Prph & AGG TTA GAA GAA GAA ACT CGC & GTA GCT TCT TGA GGA ACT CAA T \\
\hline Rtp2 & GGA ACC AGA GCC TTA GGT TA & GCC ACC TCC ATC TTC TCA TA \\
\hline Wnt4 & GTT GTT GTG AAG GTT CAT GAG T \\
\hline
\end{tabular}


bioRxiv preprint doi: https:/Aoi.org/10.1101/202Q.08.31.276253.

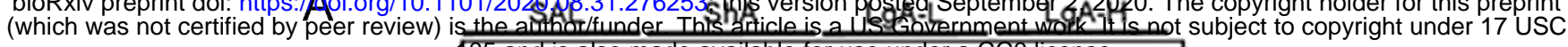

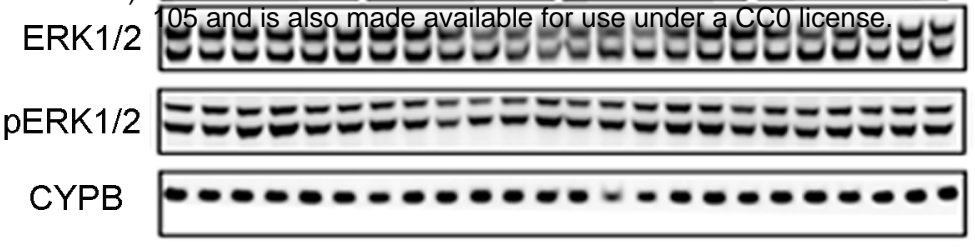

Sal O ShA $\nabla$ LgA-L $\triangle$ LgA-H

$\mathrm{B}$

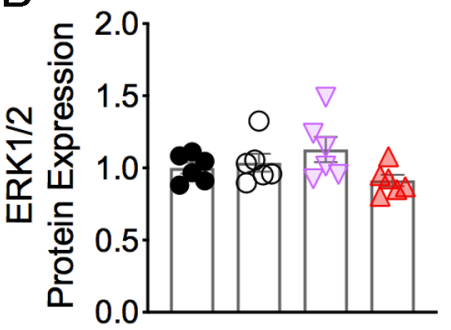

D

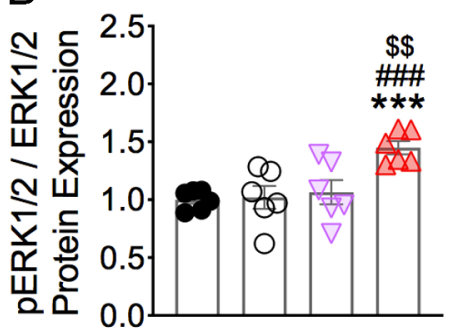

C

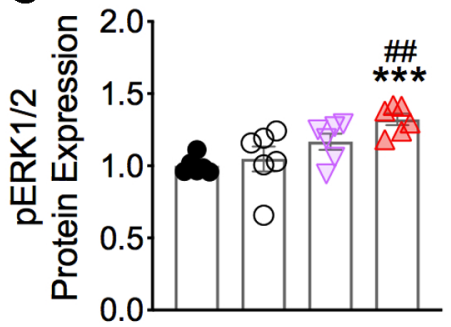

$\mathrm{E}$

$\sim{ }^{2.5}[\mathrm{R}=0.6051$

齐

焉 $1.5 \Rightarrow \nabla \Delta \Delta$

i

. $1.000 \nabla$

齐

능 은

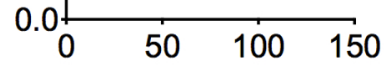

Oxycodone intake per animal $(\mathrm{mg} / \mathrm{kg})$ 
bioRxiv preprint doi: https://doi.org/10.1101/2020.08.31.276253; this version posted September 2, 2020. The copyright holder for this preprint

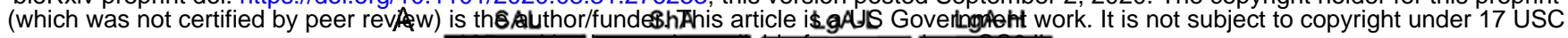

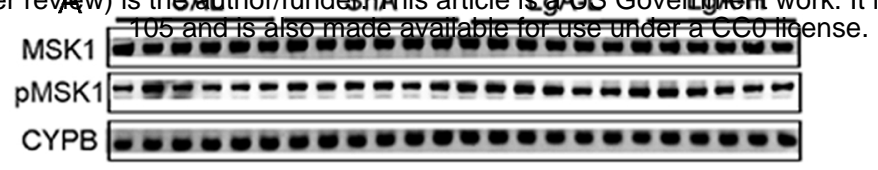

- Sal $\bigcirc$ ShA $\nabla$ LgA-L $\triangle$ LgA-H
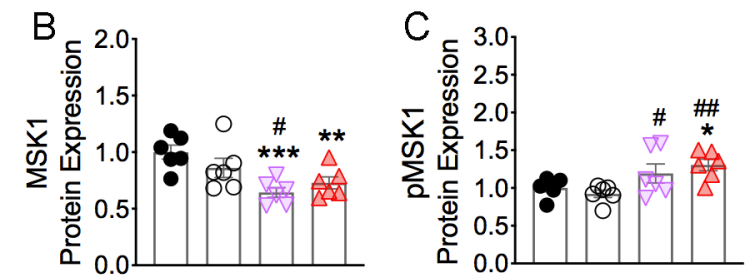

D

E

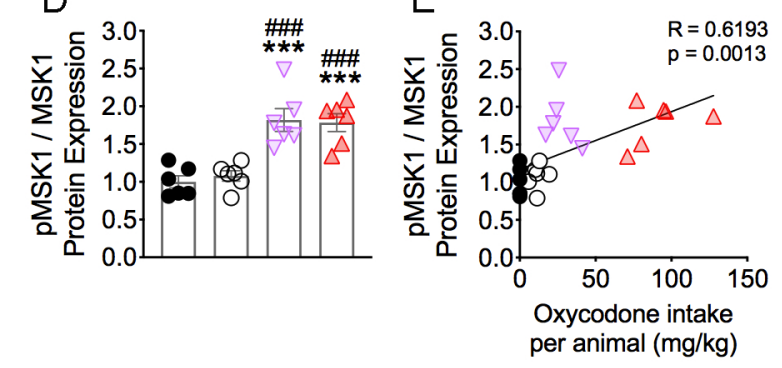

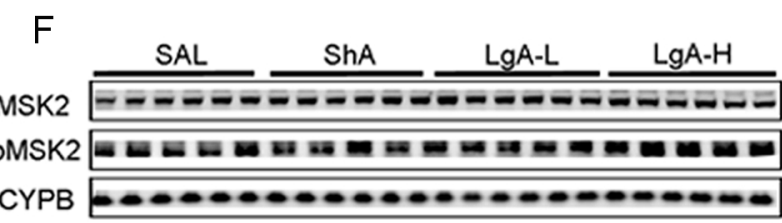

- Sal $\bigcirc$ ShA $\nabla$ LgA-L $\triangle$ LgA-H
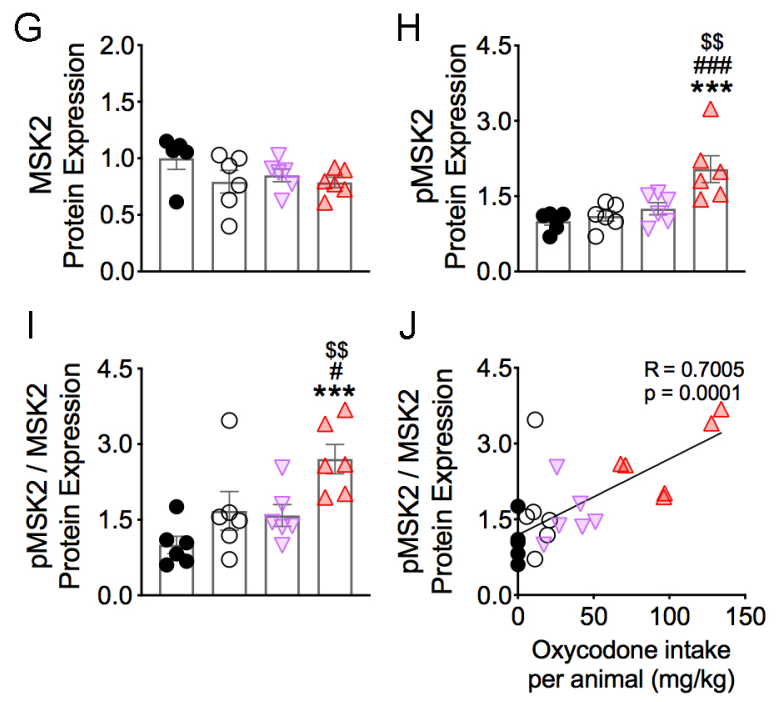


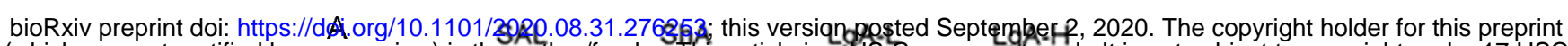
(which was not certified by peer review) CREB 405 andis also made available-for use tndera $6 \mathrm{G} 0$ lieense:

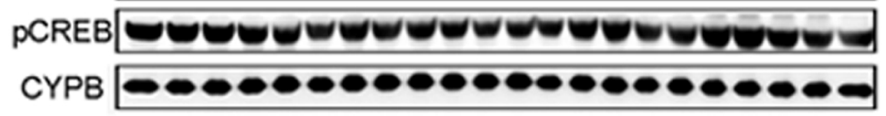

- Sal O ShA $\nabla$ LgA-L $\triangle$ LgA-H
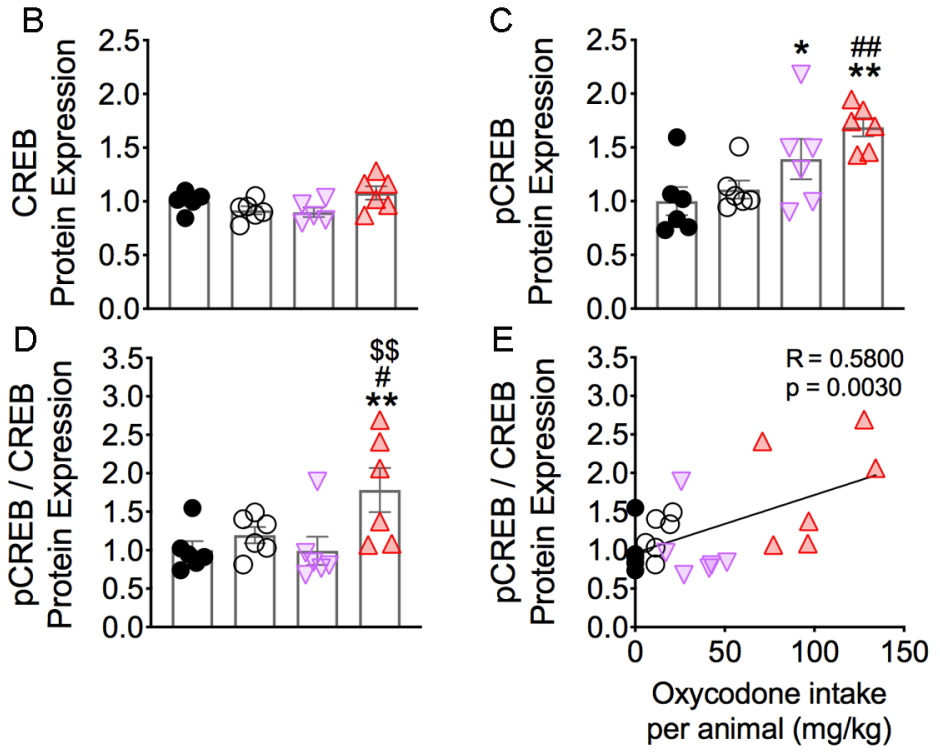
bioRxiv preprint doiAhttps://doi.org/10.110\$2/2020.08.31/36253; this vession postedgeptember 2, 2020. The copyright holder for this preprint

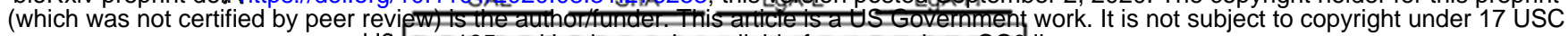
$\mathrm{H} 3=105$ and $=1$ is alsomade available for use undera $\mathrm{COO}$ license.

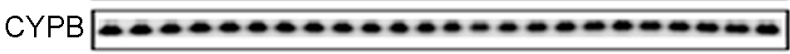

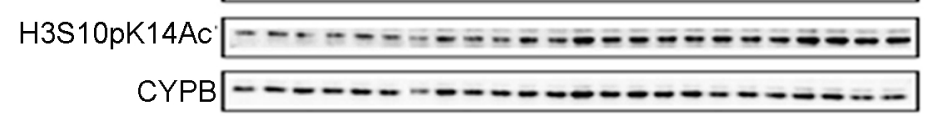

- Sal O ShA $\nabla$ LgA-L $\triangle$ LgA-H

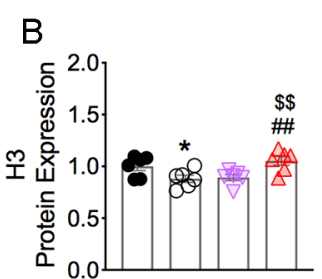

E

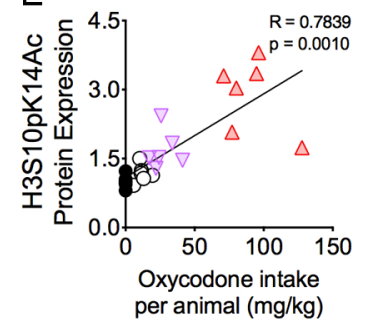

\section{$C$}

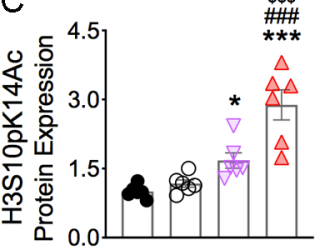

F
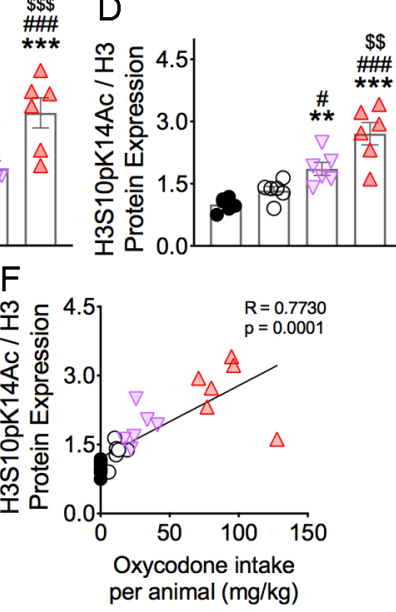
bioRxiv preprint doi: https://doi.org/10.1101/2020.08.31.276253; this version posted September 2, 2020. The copyright holder for this preprint (which was not certified by peeAreview) is the author/funder. This article is a US Government work. It is not subject to copyright under 17 USC 105 Sât is also madétávailable for usêtunder a ccoltieenise.

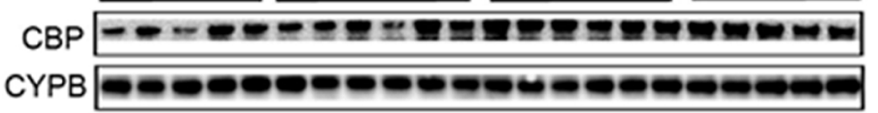

- Sal O ShA $\nabla$ LgA-L $\triangle$ LgA-H

B

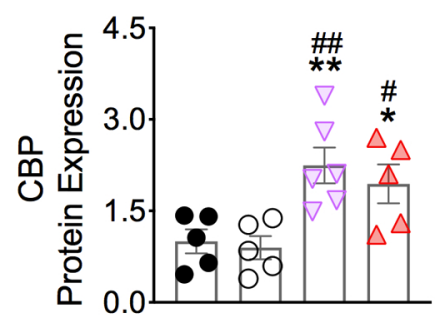

C

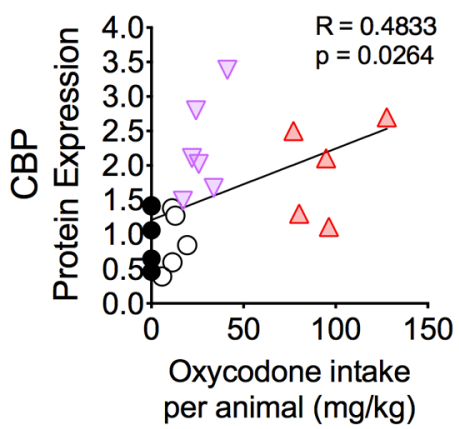

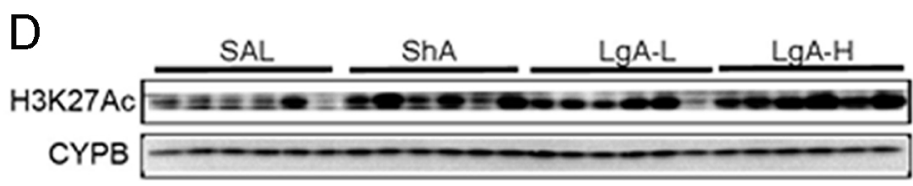

- Sal O ShA $\nabla$ LgA-L $\triangle$ LgA-H

$E$

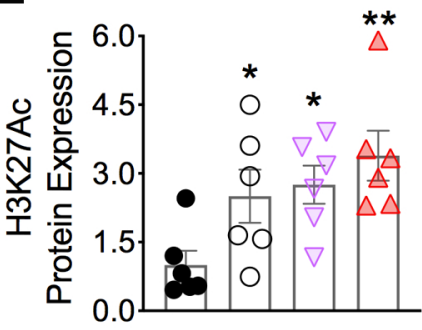

$\mathrm{G}$

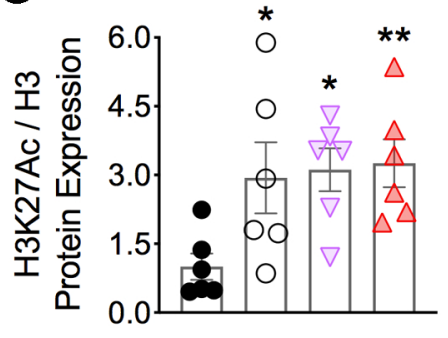

F

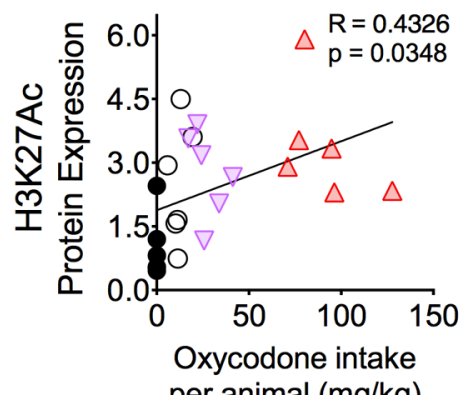

$\mathrm{H}$ per animal $(\mathrm{mg} / \mathrm{kg})$

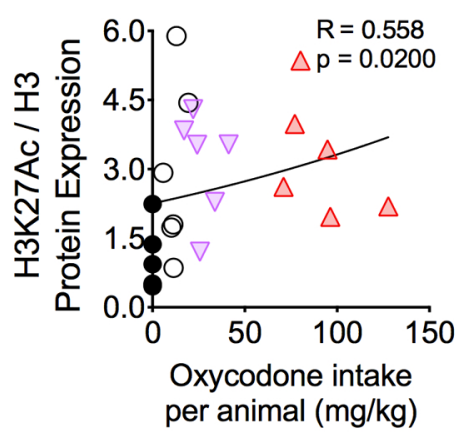


bioRxiv preprint doi: https://doi.org/10.1101/2020.08.91 Sal625ShAis vegsidn post-September 2, 2020. The copyright holder for this preprint (which was not certified by peer review) is the author/funder. This article is a US Government work. It is not subject to copyright under 17 USC
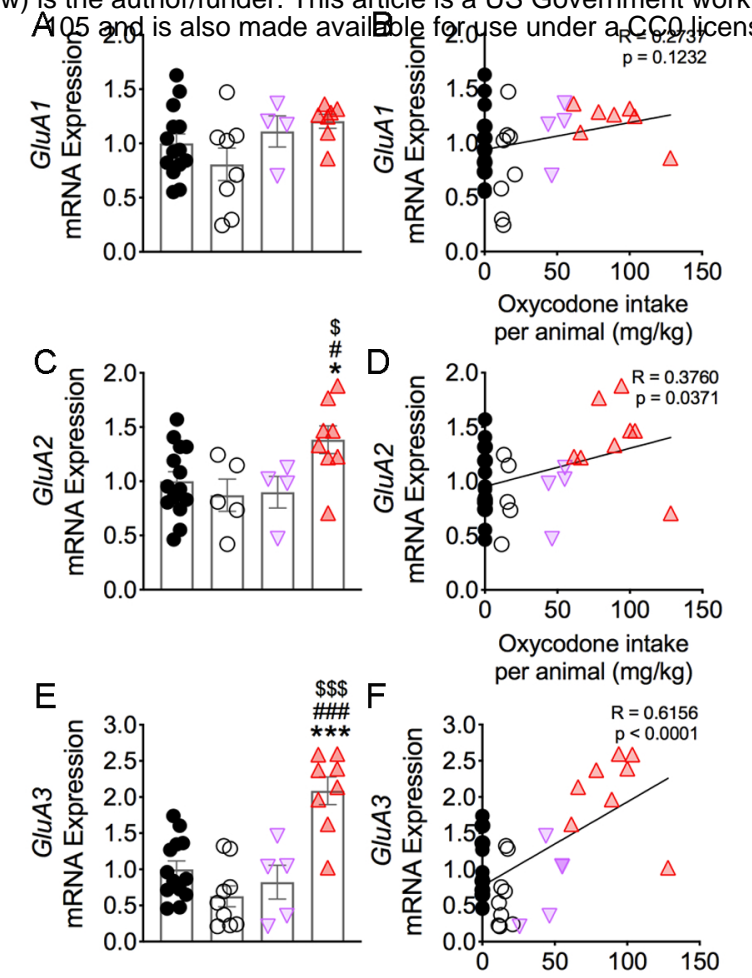

Oxycodone intake
per animal $(\mathrm{mg} / \mathrm{kg})$
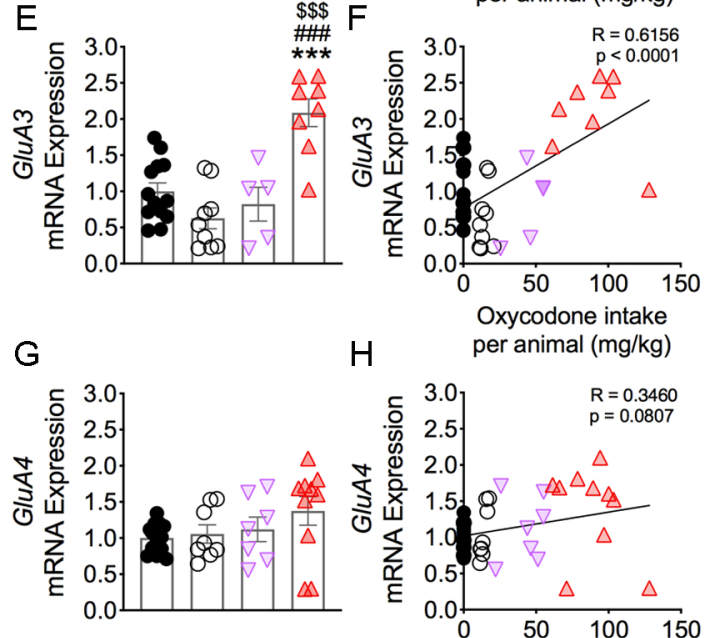

$\mathrm{H}$

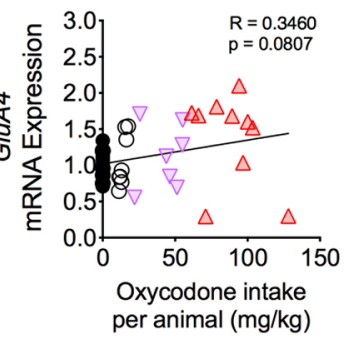


bioRxiv preprint doi: https://doi.org/10.1101/2020.08.31.276253; this version posted September 2, 2020. The copyright holder for this preprint (which was not certified by peer review) is the author/funder. This article is a US Government work. It is not subject to copyright under 17 USC 105 and is also made available for use under a CCO license.

Early withdrawal from

high amounts of oxycodone

\section{Oxycodone}

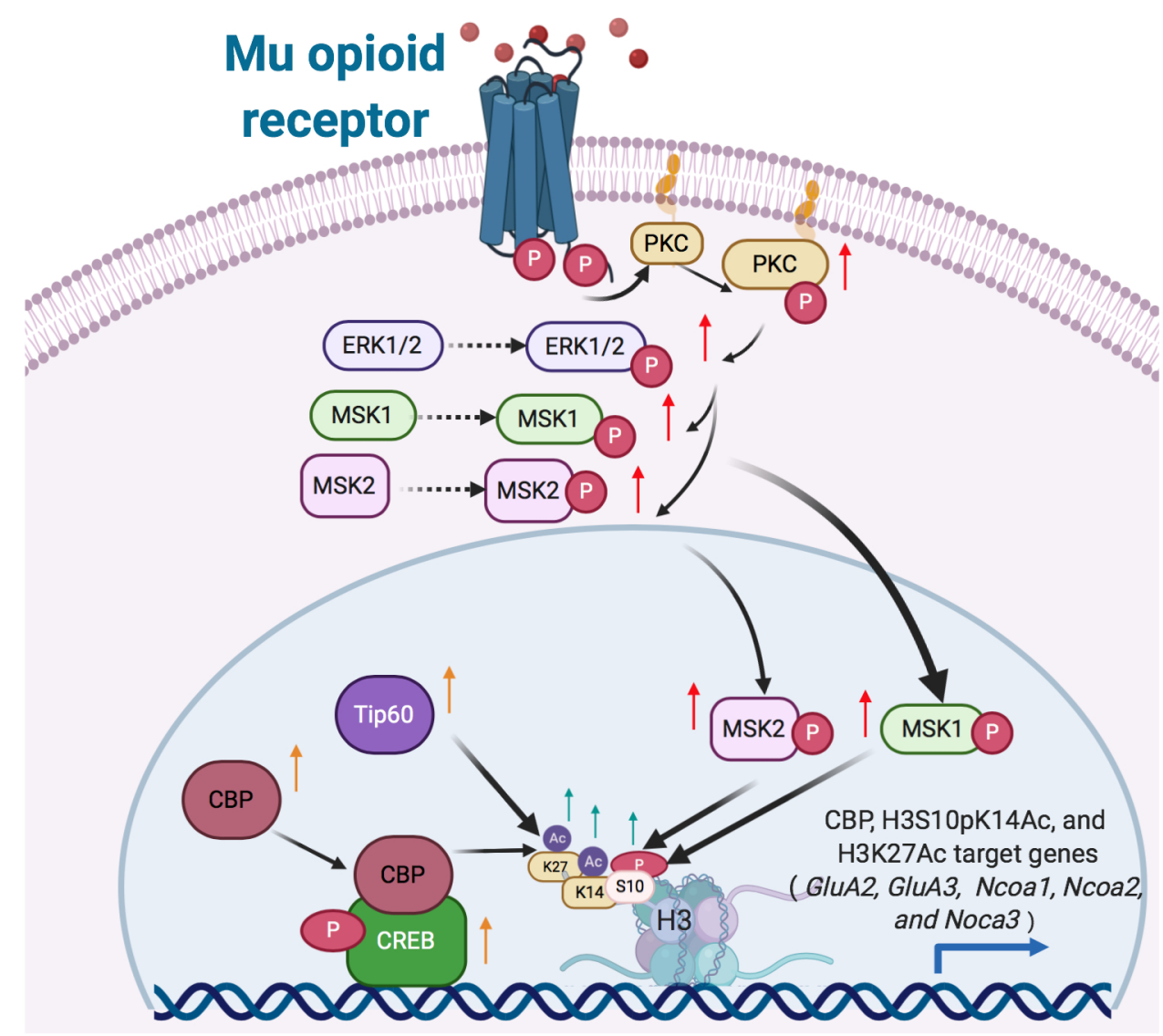


bioRxiv preprint doi: https://goi.org/10.1101/2/220.08.31.276253; this versiqnopsted September 2,2020 . The copyright holder for this preprint (which was not certified by peler review)_is the anthor/tunder.

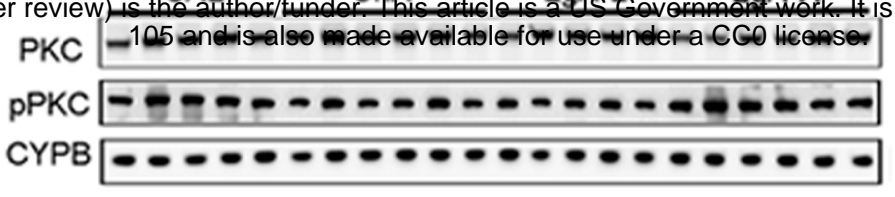

- Sal O ShA $\nabla$ LgA-L $\triangle$ LgA-H

B

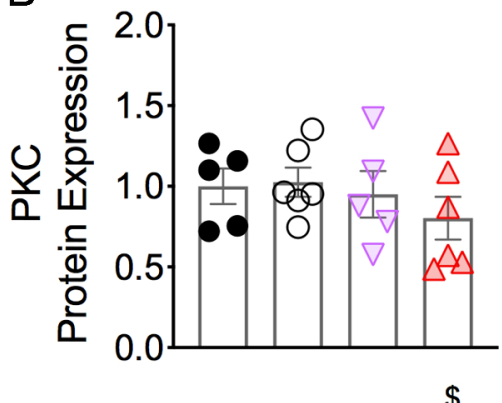

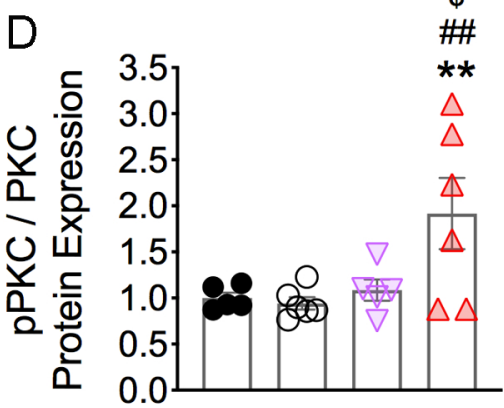

C

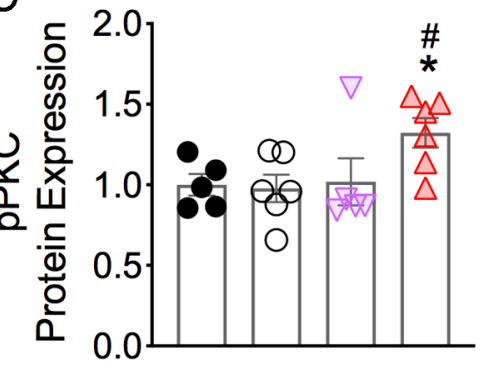

E

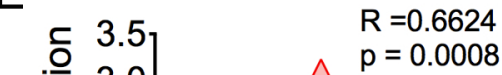

$\mathrm{p}=0.0008$

$\frac{U}{0}$

3.0

$\triangle$

2.5

2.0

产 1.0

ฉ

梶 $\triangle \triangle$

$0.0 \stackrel{50 \quad 100 \quad 150}{0}$

Oxycodone intake

per animal (mg/kg) 
bioRxiv preprint doi: https://doi.org/10.1101/2020.08.31.276253; this version posted September 2, 2020. The copyright holder for this preprint (which was not certified gy peer review) is the author/funder. This article is a US Government work. It is not subject to copyright under 17 USC Saht 05 and is alsolnade availablegartuse undega-tto license.
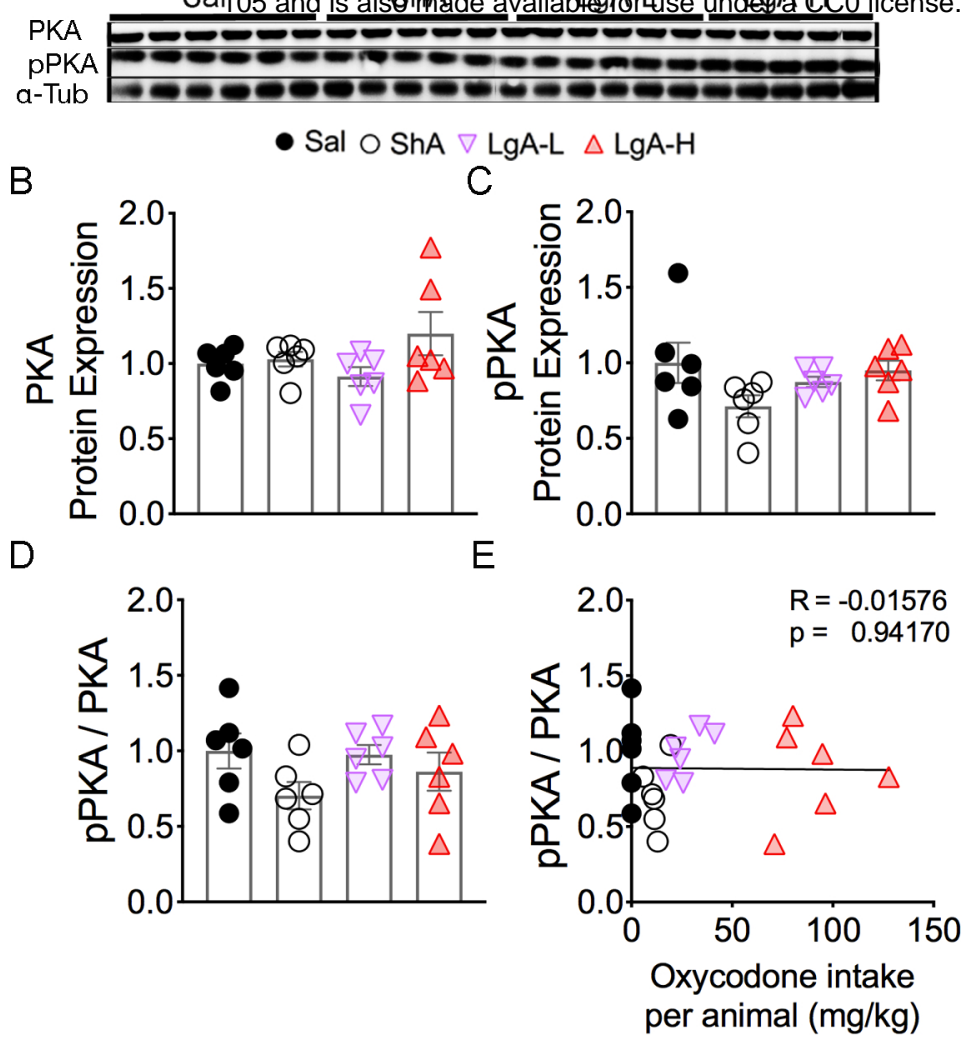


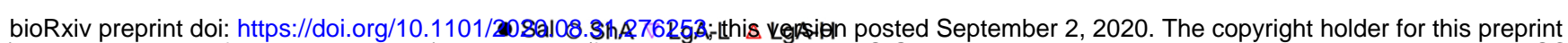
(which was not certified by peer review) is the author/funder. This article is a US Government work. It is not subject to copyright under 17 USC

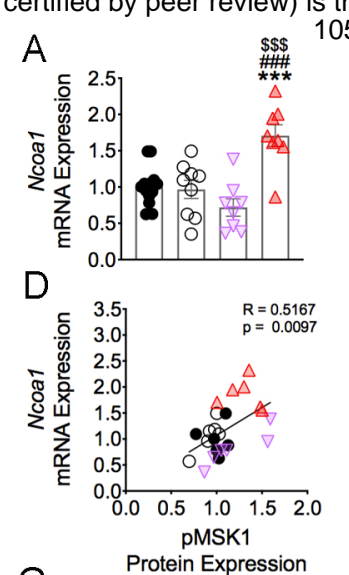

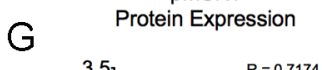

$\mathrm{E}$

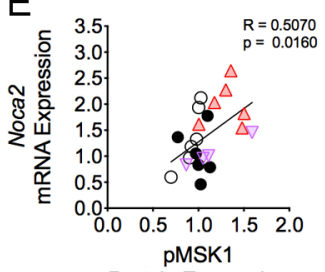

$\mathrm{H}$

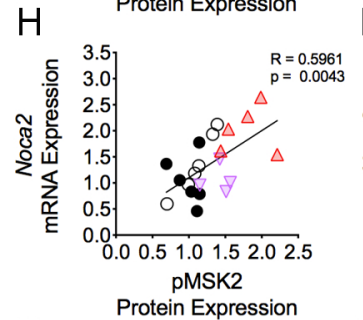

K
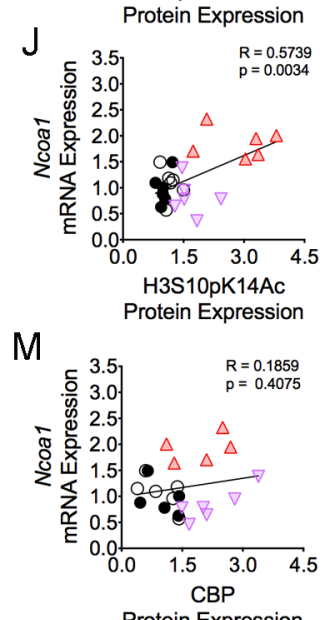

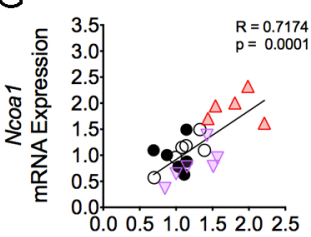

pMSK2

Protein Expression

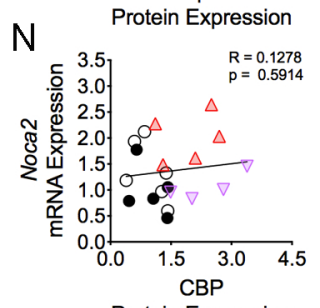

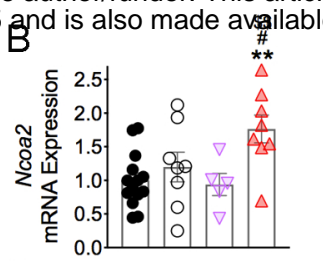

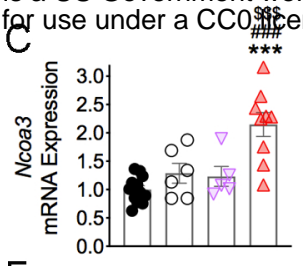

$\mathrm{F}$

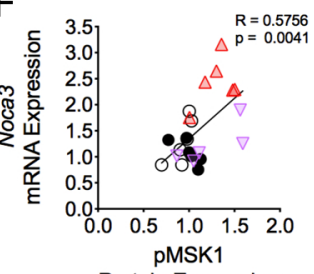

Protein Expression

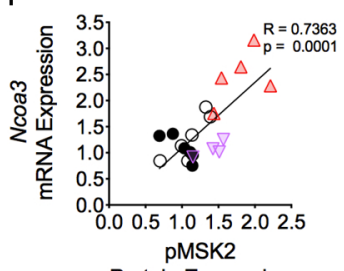

L

Protein Expression

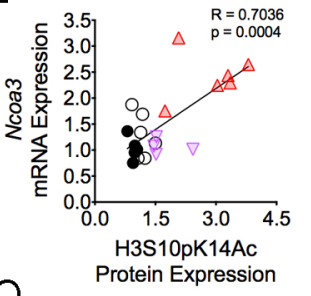

0

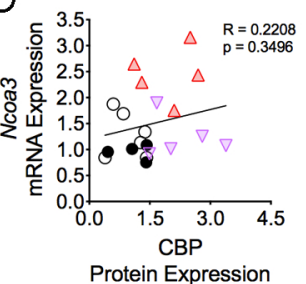


bioRxiv preprint doi: https://doi.org/10.1101/2020.08.31.276253; this version posted September 2, 2020. The copyright holder for this preprint (which was not certified by pepr review) is the author/funder. This article is a US Government work. It is not subject to copyright under 17 USC

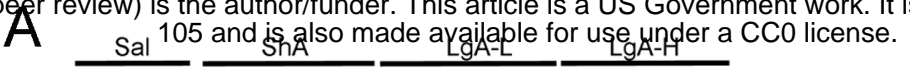

Tip60

- Sal O ShA $\nabla$ LgA-L $\triangle$ LgA-H

B

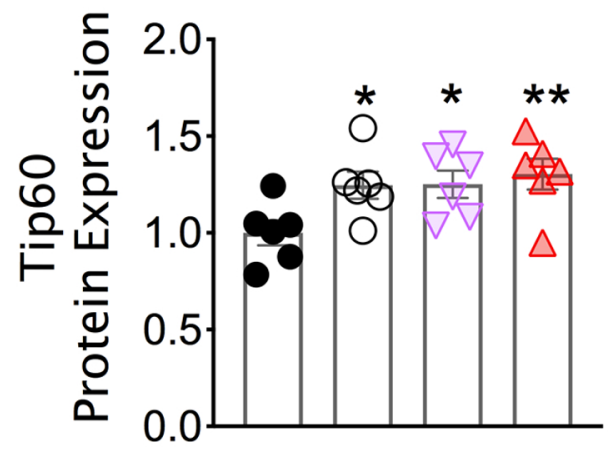

